\title{
Hydroelasticity effects on water-structure impacts
}

\author{
T. Mai ${ }^{1,2}$ (D) C. Mai ${ }^{3} \cdot$ A. Raby ${ }^{1}$ - D. M. Greaves ${ }^{1}$
}

Received: 7 October 2019 / Revised: 24 July 2020 / Accepted: 26 July 2020 / Published online: 9 August 2020

(c) The Author(s) 2020

\begin{abstract}
Local and global loadings, which may cause the local damage and/or global failure and collapse of offshore structures and ships, are experimentally investigated in this study. The research question is how the elasticity of the structural section affects loading during severe environmental conditions. Two different experiments were undertaken in this study to try to answer this question: (i) vertical slamming impacts of a square flat plate, which represents a plate section of the bottom or bow of a ship structure, onto water surface with zero degree deadrise angle; (ii) wave impacts on a truncated vertical wall in water, where the wall represents a plate section of a hull. The plate and wall are constructed such that they can be either rigid or elastic by virtue of a specially designed spring system. The experiments were carried out in the University of Plymouth's COAST Laboratory. For the cases considered here, elasticity of the impact plate and/or wall has an effect on the slamming and wave impact loads. Here the slamming impact loads (both pressure and force) were considerably reduced for the elastic plate compared to the rigid one, though only at high impact velocities. The total impact force on the elastic wall was found to reduce for the high aeration, flip-through and slightly breaking wave impacts. However, the impact pressure decreased on the elastic wall only under flip-through wave impact. Due to the elasticity of the plates, the impulse of the first positive phase of pressure and force decreases significantly for the vertical slamming impact tests. This significant effect of hydroelasticity is also found for the total force impulse on the vertical wall under wave impacts.
\end{abstract}

T. Mai

tri.mai@plymouth.ac.uk; trimc@ nuce.edu.vn

1 School of Engineering, Computing and Mathematics, University of Plymouth, Plymouth, Devon PL4 8AA, UK

2 National University of Civil Engineering, 55 Giai Phong, Hai Ba Trung, Hanoi, Vietnam

3 Thuy Loi University, 175 Tay Son, Dong Da, Hanoi, Vietnam 


\section{Graphic abstract}

Hydroelasticity effects on water-structure impacts: a impact pressures on dropped plates; $\mathbf{b}$ impact forces on dropped plates; $\mathbf{c}, \mathbf{d}, \mathbf{e}, \mathbf{f}$ wave impact pressures on the vertical walls; $\mathbf{g}$ wave impact forces on the vertical walls; $\mathbf{h}$ wave force impulses on the vertical walls: elastic wall 1 vs. rigid wall (filled markers); elastic wall 2 vs. rigid wall (empty markers)
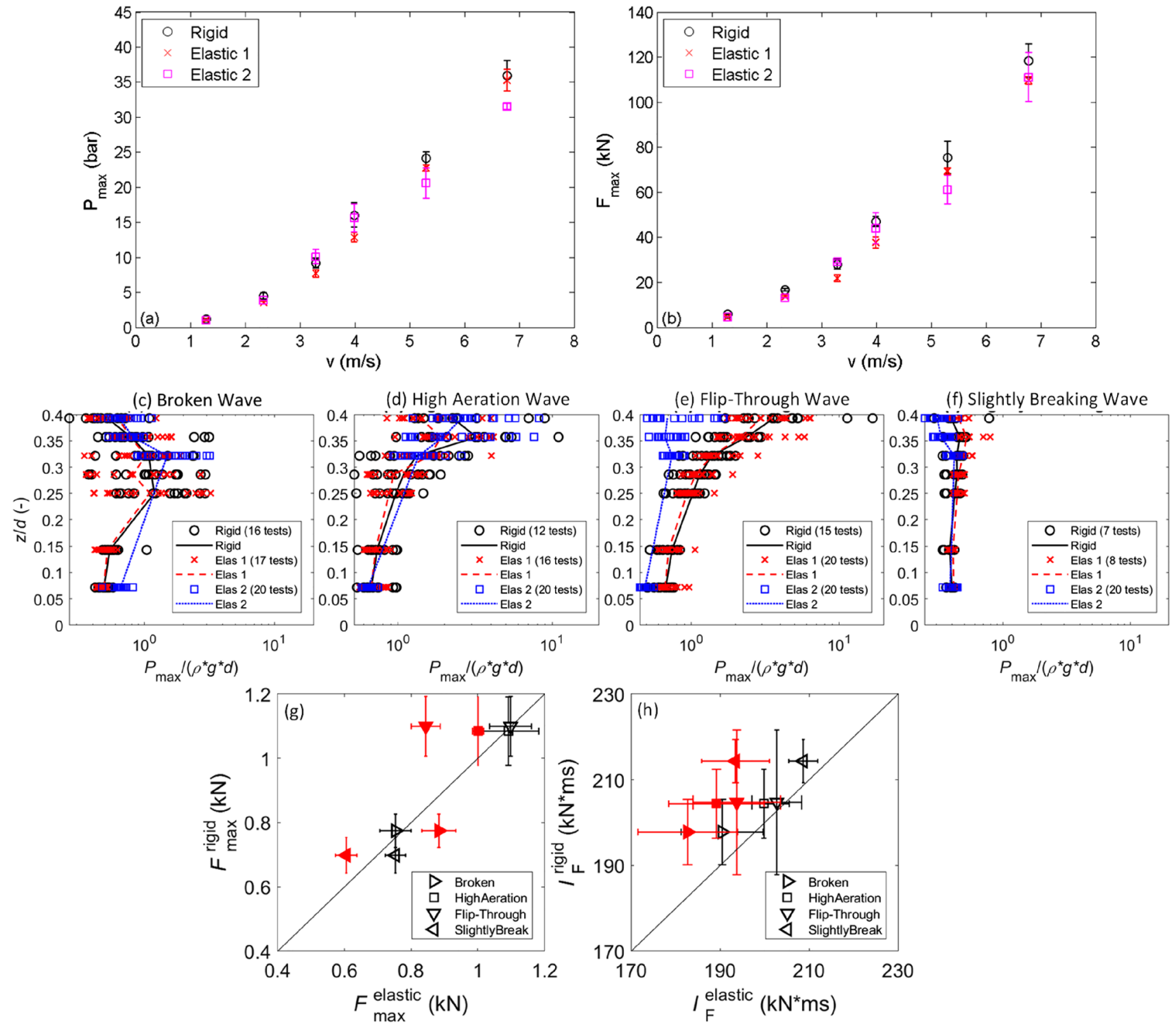

\section{Introduction}

sensitive to where the waves hit the wet deck nor to the curvature of the wave crest in the impact region (Faltinsen 1997,

Hydroelasticity in marine applications is discussed in the early works of Chuang (1970), Bishop and Price (1979), Faltinsen $(1997,2000)$ and Faltinsen et al. (2004). The research by Faltinsen $(1997,2000)$ demonstrates theoretical and experimental results that are significant for the design of offshore structures: that the maximum bending stress of a structural plate section is proportional to the drop velocity and is neither 2000). More recently, Temarel (2008) investigated the effects of hydroelasticity for a variety of marine structures such as ships, offshore platforms, very large floating structures and also aqua-culture structures, and the results show that hydroelasticity is important when predicting transient forces, such as slamming. There is a significant body of research on highspeed craft related the localized hydroelasticity effects, for 
example how the slamming loads and structural responses are affected by the elasticity of the hull/panel (Aarsnes 1994; Kvålsvold 1994; Battley et al. 2009; Stenius 2009; Stenius et al. 2011a,b; Stenius et al. 2013). With increasing ship size, craft speed, and severity of environmental loadings, the localized hydroelasticity effects have become more of an issue for achieving optimized structures. In general, hydroelasticity can be considered as a sub-category of fluid-structure interaction between flexible structure and liquid. A classic example being the hull-water impacts of high-speed craft which can produce large transient hydrodynamic impact loads on the hull/bottom structure (von Karman 1929). There is a critical influence of the impact velocity and the relative angle between the hull and water surface (the deadrise angle) on the impact loads: the impact load increases with increasing impact velocity and decreasing deadrise angle (Wagner 1932; Zhu 1995). However, with small deadrise angles the impact pressure will be decreased by an air-cushioning effect (Verhagen 1967; Lewison and Maclean 1968; Faltinsen 2014). A flexible structure will be deformed under hydrodynamic loading and this deformation of the structure will affect the local flow-field between the structure and water, and thereby the spatial and temporal pressure distributions on the structure. Kinematic and inertia effects have been identified as two types of hydroelasticity effects during an impact event (Stenius et al. 2013); kinematic effects are associated with the structure response, i.e. the structural deformation changes the geometry, velocity and acceleration conditions at the fluid-structure boundary; and on the other hand inertia effects are associated with the rise time of loading of the structure. Kinematic and inertia effects are fundamentally combined and interrelated, however a distinction between them has been discussed by Stenius (2009) and Stenius et al. (2013). Kimmoun et al. (2009) have investigated hydroelasticity experimentally by considering wave impacts on a flexible vertical wall. Their study investigated pressure distribution on the flexible wall, and deflection of the wall under various types of impact. Further, the kinematics of the fluid and fine details of the flow (air pocket) were investigated experimentally and theoretically. Their study showed fairly good agreement between these approaches.

In this present study, hydroelasticity effects on impact were experimentally investigated in a novel way by dropping a flat plate from various heights onto the water surface, with zero deadrise angle. A spring system was connected between the impact plate and the carriage to form an elastic structure, to understand the role of elasticity effect on slamming impacts on ship and offshore structures. In addition, to gain a better understanding of the physical processes involved in breaking wave impacts on a large ship or offshore structure (where elasticity of structure may have an important effect on wave impacts), various types of wave impact on a truncated vertical wall, considered to be part of a FPSO hull, have been experimentally investigated in this work. The truncated wall is an initially rigid wall that can be modified to an elastic wall by using a spring system on the rear side of the wall. Deflection of the springs, pressures and forces have been measured under the impact for both configurations.

\section{Methodology}

\subsection{Drop test}

The first series of experiments is designed to investigate hydroelasticity effects on slamming. It involves bodies slamming onto water, examples of which are the bottom and bow of a high-speed vessel, ditching of an aircraft, impact of bottom and bow of large ships like FPSO. It will model these interactions by performing a drop test with zero-degree deadrise angle.

The experimental work was carried out in the Ocean Basin in the University of Plymouth's COAST Laboratory. The ocean basin is $35 \mathrm{~m}$ long by $15.5 \mathrm{~m}$ wide and has a movable floor that allows operation at different water depths up to $3 \mathrm{~m}$. For these tests, the depth was set to $1 \mathrm{~m}$. The falling block included a rigid impact plate connected to a carriage constructed from two driver plates with a total mass of $52 \mathrm{~kg}$. A spring system was used to form elastic plates; elasticity of the plate could be changed using different spring stiffness (Mai et al. 2014; Mai 2017; Mai et al. 2019a). The falling block could be freely dropped in a $4 \mathrm{~m}$ high vertical guide frame fixed on the gantry crossing over the ocean basin. After each test, the falling block was lifted up to the tested drop height by a crane (see Fig. 1a, b). The impact plate was $0.25 \mathrm{~m}$ long, $0.25 \mathrm{~m}$ wide and $0.012 \mathrm{~m}$ thick. The impact velocity varied between 1 and $7 \mathrm{~m} / \mathrm{s}$ by varying the drop height of the impact plate in the experiments to investigate the relationship between impact velocity, maximum pressure and force at impact. Pressures under the impact plate were measured by five miniature pressure transducers (FGP Sensors XPM10 having measurement range of up to 100 bar) installed at various locations on the lower face of the plate. The velocity of impact was estimated by integrating data recorded by an accelerometer (Model 4610 with range of up to $200 \mathrm{~g}$ or $500 \mathrm{~g}$, in which $\mathrm{g}$ is the gravity acceleration) mounted on the top of the impact plate. A displacement sensor (Model LVDTGCA500) was used to measure deflection of the springs under slamming impact. The geometry of the impact plate, the vertical distribution of mass and the configuration of the instrumentation on the impact plate are presented in Figs. 1c-e, 2. The sampling frequency was $50 \mathrm{kHz}$ for pressure transducers, accelerometer and displacement sensors. This rate was sufficient to distinguish all the features of interest in the pressure and acceleration time histories. The velocity was integrated from the measured acceleration and the impact velocity is 


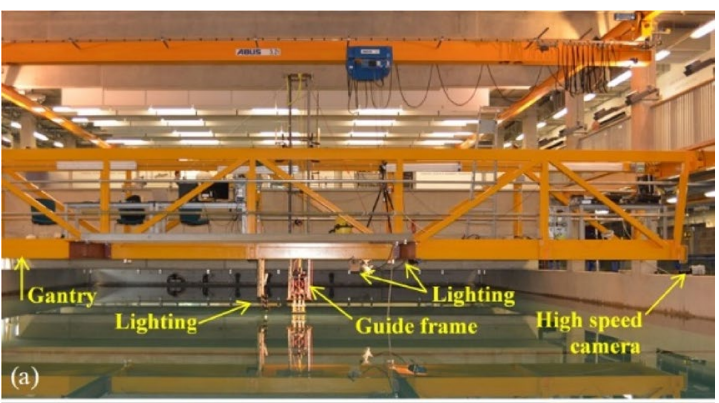

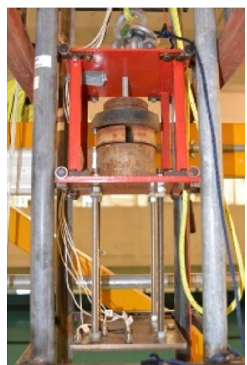

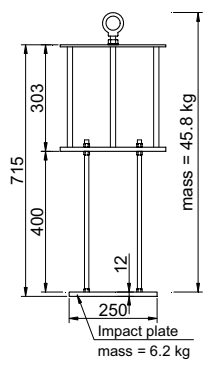

(c)
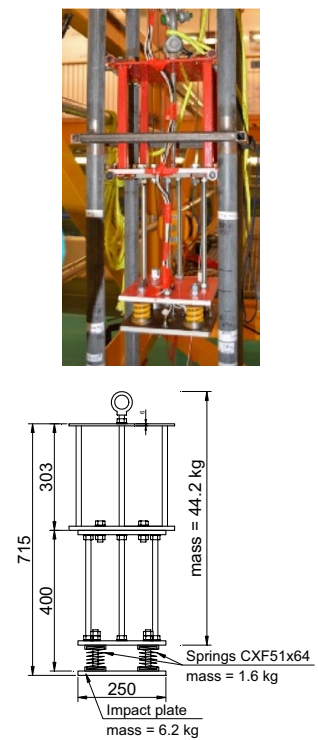

(d)
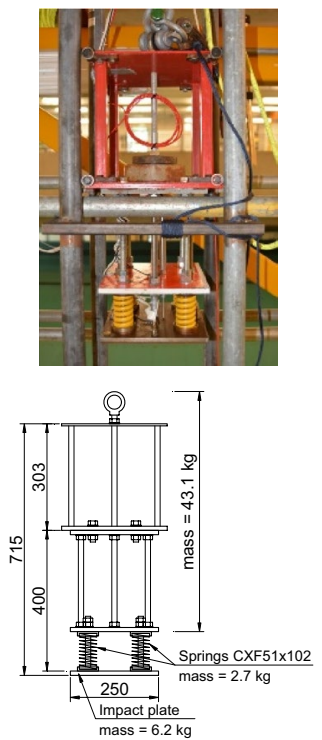

(e)

Fig. 1 a Overview and $\mathbf{b}$ closer view of drop test rig in the Ocean Basin. Configuration and vertical distribution of mass of the impact plates: $\mathbf{c}$ rigid plate; $\mathbf{d}$ elastic plate 1 -with springs CXF51 $\times 64$ and e elastic plate 2 -with springs CXF51 $\times 102$. Units in $\mathrm{mm}$

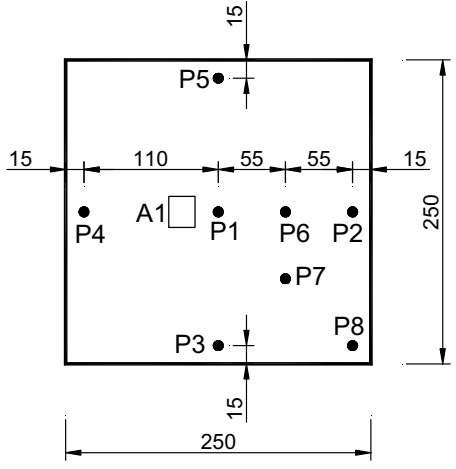

Fig. 2 Configuration of instrumentation on the impact plate: P1-P8 are pressure transducers; A1 is the accelerometer. Units in $\mathrm{mm}$

the maximum velocity obtained at the time when the impact plate is about to hit the water surface. The impact velocity was varied from 1 to $7 \mathrm{~m} / \mathrm{s}$ by changing the drop height.

\subsection{Wave impact test}

The second series of experiments was the offshore breaking wave impacts on a truncated vertical wall, representing a hull section of an FPSO. Various types of wave impact were generated and tested to identify the most violent impact type for ship and offshore structures. Furthermore, elasticity of the wall was tested to investigate how it affects impact loadings on the structure.

The experimental work was carried out in the sediment wave flume, also in the COAST Laboratory. The wave flume is $35 \mathrm{~m}$ long with a width of $0.6 \mathrm{~m}$, a height of $1.2 \mathrm{~m}$, and with a maximum still water depth of $0.8 \mathrm{~m}$. A schematic of the physical model setup is given in Fig. 3. The truncated vertical wall (Plate 1) is an aluminium plate of $0.56 \mathrm{~m}$ width by $0.6 \mathrm{~m}$ height and $0.012 \mathrm{~m}$ thickness connected to a rigid part (Plates 2 and 3) by four springs. Plate 2 and 3 were mounted on a support frame via a low profile load cell and Plate 4. There were $0.02 \mathrm{~m}$ gaps on both sides of the tested model to ensure no friction between the model and the flume side walls, which would have affected the deformation of the springs and the load measurement. The spring system can incorporate springs of different stiffness and can also be locked to obtain a rigid wall impact model (Mai et al. 2015; Mai 2017; Mai et al. 2019a). Pressures under wave impact were measured by FGP XPM10 pressure sensors installed at 7 locations on the impact wall. A low profile load cell was used with an inline DC amplifier (Model 140) to measure total force on the wall. Accelerometers (Model 4610) were used to measure vibration of the structure under wave impact. The configuration of the instrumentation on the impact plate is presented in Fig. 3c. Figure 4 shows more details of the mass horizontal distribution of the tested walls. The pressure, force, deflection and acceleration data were sampled at $35 \mathrm{kHz}$ frequency. This sampling frequency was smaller than that used in the drop test due to the larger number of measurement instruments and the RAM (Random-access memory) limitation of the computer used in this experiment.

Thirteen resistance-type wave gauges were used to measure water elevation along the wave flume, of which five wave gauges were used to measure wave profile in front of the 


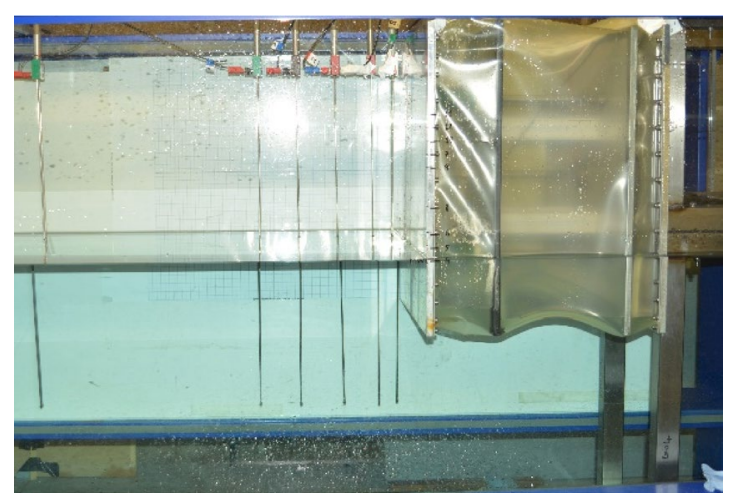

(a)

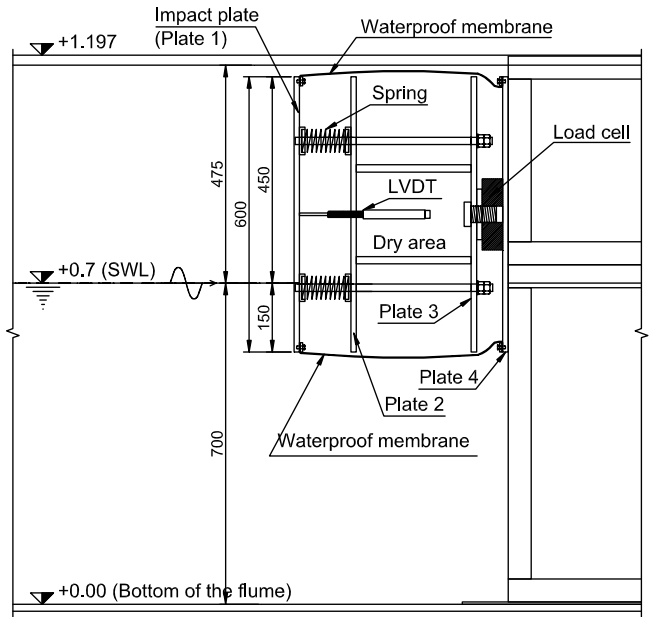

(b)

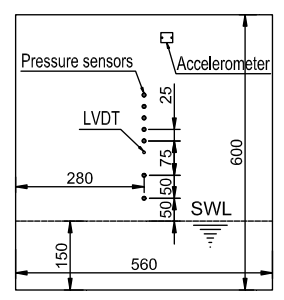

(c)

Fig. 3 a, b Side view of the tested model in the $35 \mathrm{~m}$ long wave flume; c configuration of instrumentation on the impact wall. Units in mm

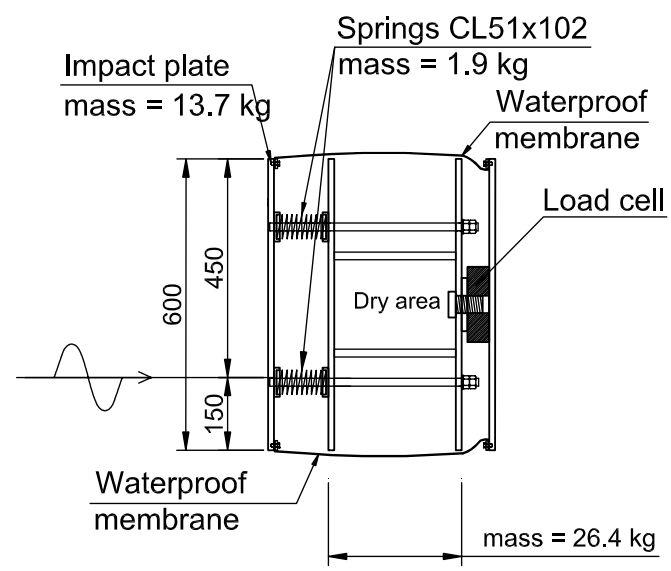

(a)

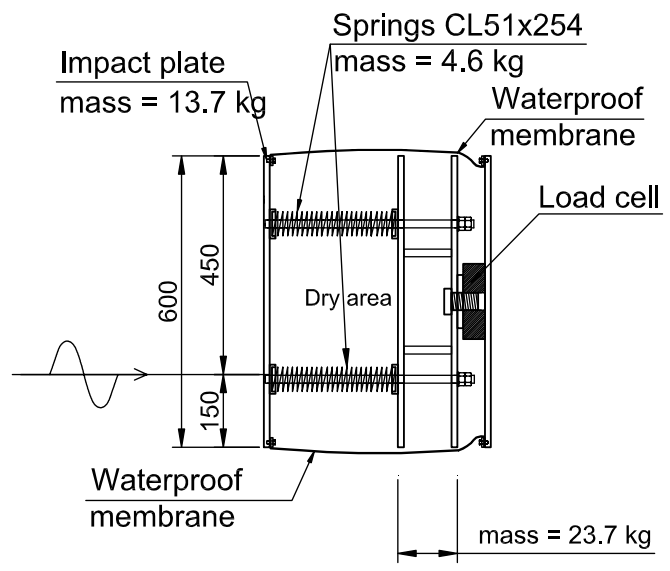

(b)

Fig. 4 Mass horizontal distribution of the wall: a with springs CL51 $\times 102$; $\mathbf{b}$ with springs CL $51 \times 254$. Units in mm

model during impact (Fig. 3b). The wave gauge data were sampled at $128 \mathrm{~Hz}$ frequency.

A focusing technique was applied to generate different types of wave impact by changing the focus location $X_{\mathrm{f}}$ from the wave paddle (Kimmoun et al. 2010). Focus wave groups were generated using NewWave (Tromans et al. 1991) focusing with an underlying JONSWAP spectrum $(\gamma=3.3)$. Four different wave impact types were generated by changing the focus location. The distance between the front impact plate (Plate 1) and the wave paddle was $26.9 \mathrm{~m}$. The target focus points were located at $X_{\mathrm{f}}=28.54 \mathrm{~m}, 28.84 \mathrm{~m}, 29.04 \mathrm{~m}$ and $29.44 \mathrm{~m}$ from the wave paddle for the broken (Fig. 5a), highaeration (Fig. 5b), flip-through (Fig. 5c) and slightly breaking (Fig. 5d) waves, respectively. The experimented wave characteristics had the significant wave height $H_{\mathrm{s}}=0.163 \mathrm{~m}$, peak wave period $T_{\mathrm{p}}=1.601 \mathrm{~s}$ and the number of wave components
$N=116$. The wave conditions $\left(H_{\mathrm{s}}\right.$ and $\left.T_{\mathrm{p}}\right)$ were scaled from prototype by a factor of $1: 65$ of the 100 year extreme significant wave height at the Cleeton platform in the Southern North Sea (Williams 2008). The tested water depth used in this study was $0.7 \mathrm{~m}$. See Mai et al. (2015), Mai (2017) and Mai et al. (2019b) for more detailed information.

\section{Results and discussions}

\subsection{Hydroelasticity effects on slamming}

\subsubsection{Typical time history of slamming}

Typical motion time histories for the impact of the $52 \mathrm{~kg}$ rigid and elastic plates with about $4 \mathrm{~m} / \mathrm{s}$ impact velocity, are shown in 


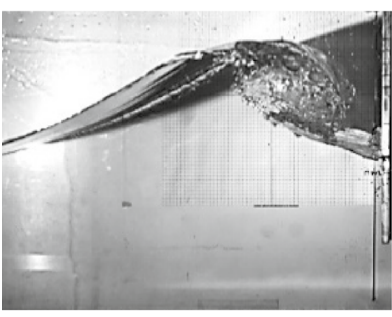

(a) Broken

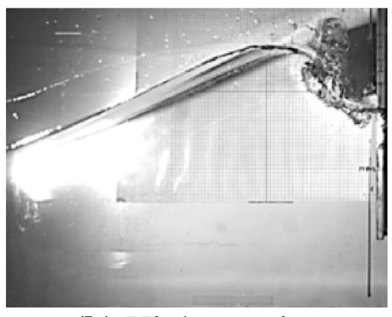

(b) High aeration

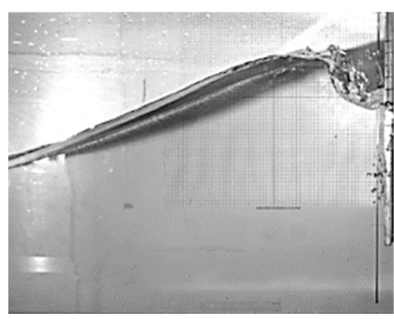

(c) Flip-through

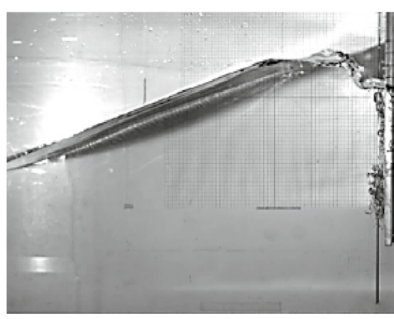

(d) Slightly breaking

Fig. 5 Snapshorts of the tested wave profiles
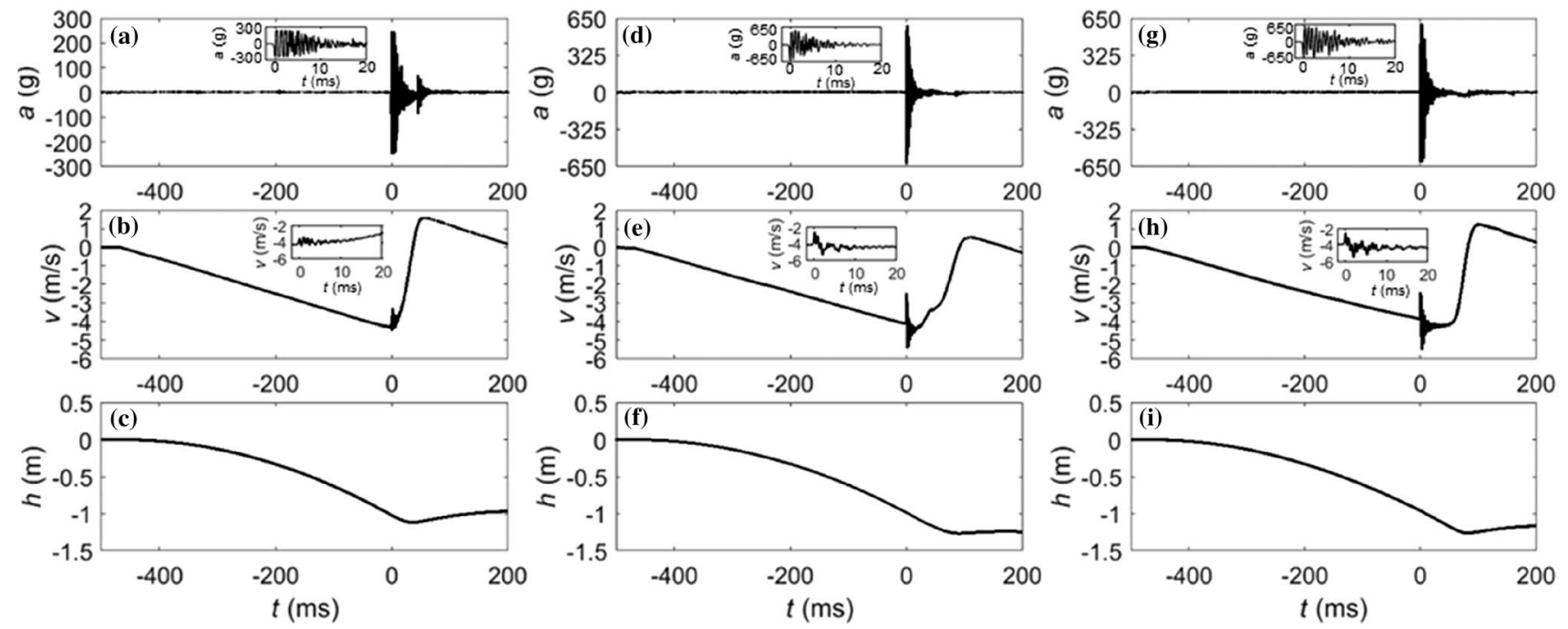

Fig. 6 Typical time-history of acceleration, velocity and displacement of the $52 \mathrm{~kg}$ plates with $v \approx 4.0 \mathrm{~m} / \mathrm{s}$ : Rigid plate (a-c); Elastic plate 1 (d-f); Elastic plate $2(\mathbf{g}-\mathbf{i})$

Fig. 6a-c for the rigid plate, Fig. $6 \mathrm{~d}-\mathrm{f}$ for elastic plate 1 (using springs CXF51 $\times 54$ ) and Fig. $6 \mathrm{~g}-\mathrm{i}$ for elastic plate 2 (using springs CXF51 $\times 102$ ). The acceleration signals are clipped in Fig. 6a, d, g because the measured accelerations exceeded the $200 \mathrm{~g}$ and $500 \mathrm{~g}$ limits of the accelerometer in those tests. Figure $6 \mathrm{~b}, \mathrm{e}, \mathrm{h}$ show that the velocity is zero at the start of the tests and then increases linearly during the free falling of the impact plates until a maximum velocity is obtained. At the instant of reaching its maximum velocity, the impact plates start to decelerate and this corresponds to the first contact with the water surface. The velocity of the impact plates fluctuates for about $30 \mathrm{~ms}$, then decreases smoothly to zero and changes its direction due to the safety rope, which was connected to the carriage and used to stop the carriage from leaving the guide frame. The clipping of acceleration signals has an effect on the integrated velocity after the plate hit the water surface, but it does not affect the maximum velocity (the impact velocity). It is shown that the oscillations of acceleration and velocity increase with increasing elasticity of the plate (see small graphs in Fig. 6a, b, d, e, g, h. In Fig. 6c, f, i the integrated displacement of the impact plates during the test is shown.
The associated pressures and deflection of springs and the integrated force are presented in Fig. 7 for the rigid and elastic plates 1 and 2. Figure 7a, c, f present the pressures measured at locations $\mathrm{P} 1$ and $\mathrm{P} 2$ on the rigid plate, elastic plates 1 and 2, respectively (see Fig. 2 for the measured pressure locations). As was found for impact of the rigid plate (Fig. 7a), the impact pressures at locations near the edge (P2) are always attained earlier than the others at the centre of the impact plate (P1) and they are always much smaller than those at the plate centre under violent impacts (Fig. 7c, f). The impact pressure at the centre (P1) of the rigid plate is 14.75 bar (Fig. 7a) and this is higher than those on the elastic plate 1 (13.1 bar in Fig. 7c) and elastic plate 2 (12.73 bar in Fig. 7f). Similarly, the impact pressure near the edge (P2) of the elastic plate 1 (5.11 bar) and elastic plate 2 (5.05 bar) are slightly smaller than that of the rigid plate $(5.38 \mathrm{bar})$. The integrated force and the measured deflection of springs are respectively presented in Fig. 7d, e for the elastic plate 1 , and in Fig. $7 \mathrm{~g}$, $\mathrm{h}$ for the elastic plate 2. The maximum force of $37.82 \mathrm{kN}$ on the elastic plate 1 due to impact with $v=4.11 \mathrm{~m} / \mathrm{s}$ is very slightly higher than that on the elastic 

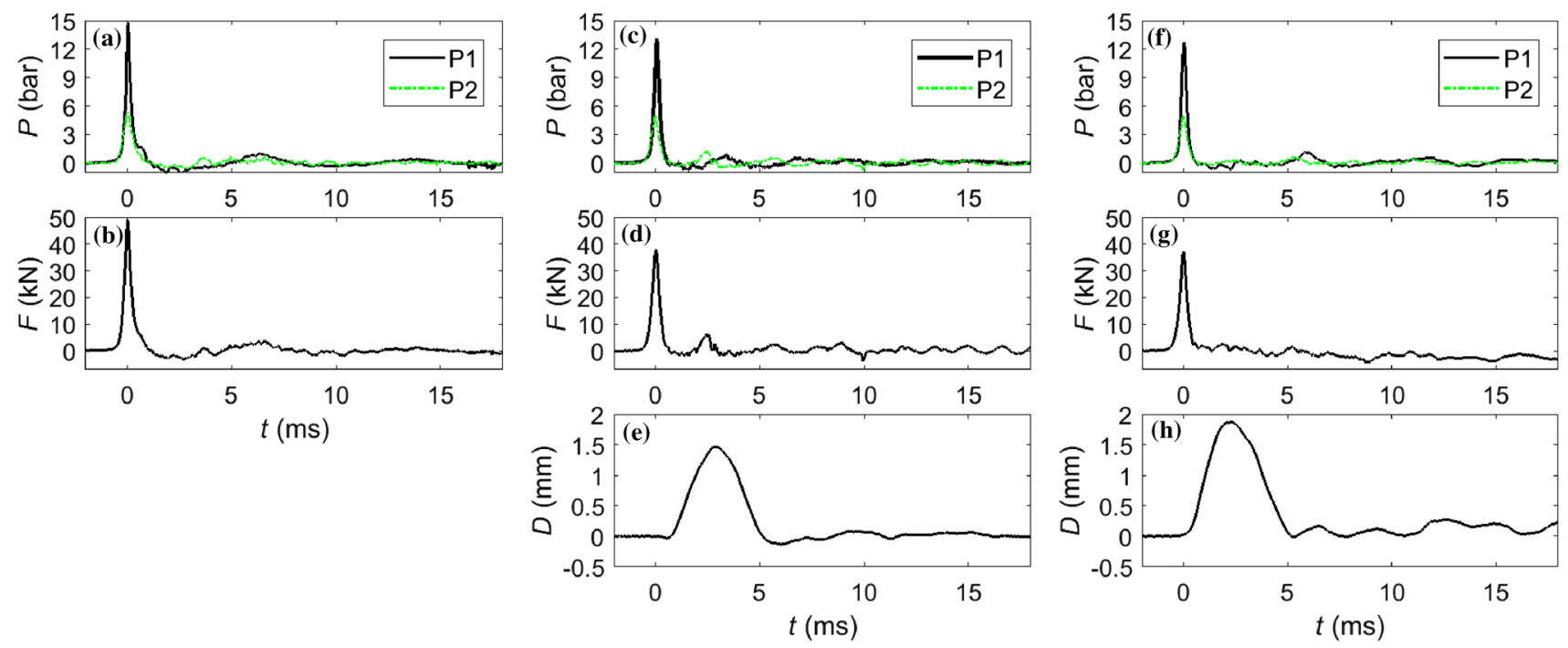

Fig. 7 Typical time-histories of pressures, force and deflection of springs of the $52 \mathrm{~kg}$ plates with $v \approx 4.0 \mathrm{~m} / \mathrm{s}$ : Rigid plate (a, b); Elastic plate 1 (c-e); Elastic plate $2(\mathbf{f}-\mathbf{h})$

plate 2 due to impact with $v=3.90 \mathrm{~m} / \mathrm{s}$, where the maximum force was $37.00 \mathrm{kN}$. In contrast, the maximum deflection of the springs of the elastic plate $1\left(D_{\max }=1.47 \mathrm{~mm}\right)$ is proportionally much smaller than that for the elastic plate 2 $\left(D_{\max }=1.87 \mathrm{~mm}\right)$. The maximum deflection was attained at about $2-3 \mathrm{~ms}$ after the impact $(t=0)$. This delay was also found in the drop test on regular waves presented by Faltinsen $(1997,2000)$. The natural period of a spring can be estimated from $T=2 \pi\left(m_{\mathrm{s}} / k\right)^{0.5}$, where $m_{\mathrm{s}}$ is the mass of spring in $\mathrm{kg}$ and $k$ is the spring rate in $\mathrm{N} / \mathrm{m}$. Therefore, the natural periods of the springs CXF51 $\times 54\left(m_{\mathrm{s} 1}=0.41 \mathrm{~kg}\right.$ and $k_{\mathrm{s} 1}=765,538 \mathrm{~N} / \mathrm{m}$ for a single spring) and CXF51 $\times 102$ ( $m_{\mathrm{s} 2}=0.66 \mathrm{~kg}$ and $k_{\mathrm{s} 2}=397,400 \mathrm{~N} / \mathrm{m}$ for a single spring) are calculated to be $T_{1}=4.6 \mathrm{~ms}$ and $T_{2}=8.1 \mathrm{~ms}$, respectively. The rise time of the maximum deflections is about $2.2 \mathrm{~ms}$ for both spring types Fig. 7e, h. This rise time is about a half of the natural period of the spring CXF5 $1 \times 54\left(T_{1}=4.6 \mathrm{~ms}\right)$ and about one quarter of the natural period of the spring CXF51 $\times 54\left(T_{2}=8.1 \mathrm{~ms}\right)$. The natural frequencies of the four springs and the impact plate are about $99.5 \mathrm{~Hz}$ and $67.5 \mathrm{~Hz}$ for the elastic plate 1 (using springs CXF51×54) and the elastic plate 2 (using springs CXF51 $\times 102$ ), respectively. See Table 1 in Appendix A for the detailed estimation of the dry natural frequency of the four springs and the impact plate.

Distinct post-impact pressure oscillations under impact of the elastic plates onto the water surface were observed in this experiment. Pressure P1, P2 and P6 are presented and compared with the impact of the rigid plate in water in Fig. 8, 9,10 , in which the impact velocities were $1.28 \pm 0.07 \mathrm{~m} / \mathrm{s}$, $4.08 \pm 0.17 \mathrm{~m} / \mathrm{s}$ and $6.96 \pm 0.18 \mathrm{~m} / \mathrm{s}$, respectively. In Fig. 8 , the first pressure peak decreases with increasing elasticity of the plate. The oscillation after the impact is believed to be caused by the oscillation of the trapped air between the impact plate and water surface, which has been discussed in previous studies (Ma et al. 2016; Mai 2017; Mai et al. 2019a). The FFT spectra of the measured pressures are given in the right hand plots in the figures. Under higher impact velocities $(v=4.08 \pm 0.17 \mathrm{~m} / \mathrm{s}$ and $6.96 \pm 0.18 \mathrm{~m} / \mathrm{s})$, there are significant differences in the post-impact oscillations between the rigid plate and elastic plates with higher frequency peaks evidence for the elastic plates (Figs. 9, 10). Significant differences between the pressure traces for rigid and flexible panels were also found from the controlled water slam test of composite hull panels presented by Battley et al. (2009), Stenius (2009) and Stenius et al. (2011a). Higher oscillation frequency of the pressure under impact of an elastic plate was also observed by Tenzer et al. (2015). In the present study, it is clearly seen for the elastic plates that there are higher order frequencies in the pressure oscillations under high impact velocities and most of these oscillation frequencies are higher than the natural frequency $(\sim 500 \mathrm{~Hz})$ of the falling block, carriage and support frame set-up for the rigid plate test (Figs. 9, 10). As it was found in the impact of the rigid plate in water (Ma et al. 2016; Mai 2017; Mai et al. 2019a), the high peak frequencies $(139.9 \mathrm{~Hz}$ and $319.7 \mathrm{~Hz})$ of the post-impact pressures (Figs. 8b, d, f, 9b, d, f, 10b, d, f) may due to the repeated compression and expansion of the different diameter trapped air bubbles when the impact plate is about to hit the water surface. The trapped air in flat plate impacts has been visually found in previous studies (Mai et al. 2014; Mayer and Krechetnikov 2018). The $139.9 \mathrm{~Hz}$ and $319.7 \mathrm{~Hz}$ are far from the $500 \mathrm{~Hz}$ natural frequency of the falling block, carriage and support frame set-up for the rigid plate test. These frequency $(139.9 \mathrm{~Hz}$ and $319.7 \mathrm{~Hz})$ are also higher than the natural frequencies of the four springs 
and the impact plate which are about $99.5 \mathrm{~Hz}$ and $67.5 \mathrm{~Hz}$ for the elastic plates 1 and 2, respectively. As a result of the shock wave traveling through the air gap along the width of the rigid plate (Mai 2017; Mai et al. 2019a), a second pressure shock was observed at an early stage $(t=0.6 \mathrm{~ms})$ under impact velocity of $6.96 \pm 0.18 \mathrm{~m} / \mathrm{s}$ (the solid lines in Fig. 10a), but this second pressure shock appears at later stages, at about $t=3.2 \mathrm{~ms}$ and $3.6 \mathrm{~ms}$ for the elastic plates 1 and 2 (the dashed and dotted lines in Fig. 10a) and these later appearances of the second pressure shocks seem to be caused by a combined effect of the plate elasticity and the trapped air under the impact. There is no evidence of this second pressure peak from the previous experimental drop test studies in which plates with large deadrise angles $\left(5^{\circ}\right.$ and $10^{\circ}$ ) were used and so no air bubble could be trapped under the plate. Similar to the impact of the rigid plate (Ma et al. 2016; Mai 2017; Mai et al. 2019a), the impact of elastic plates have shown many high frequency peaks of the corresponding discrete impact pressure events and these high frequencies are slightly different between the rigid and elastic plates (Figs. 8b, d, f, 9b, d, f, 10b, d, f).

\subsubsection{Impact pressure and force on rigid and elastic plates}

Figure 11 presents the impact pressures and forces under the impacts of the rigid and elastic plates. The impact pressures are presented in Fig. 11a for the measured location at the centre of the plate (P1). The impact forces are shown
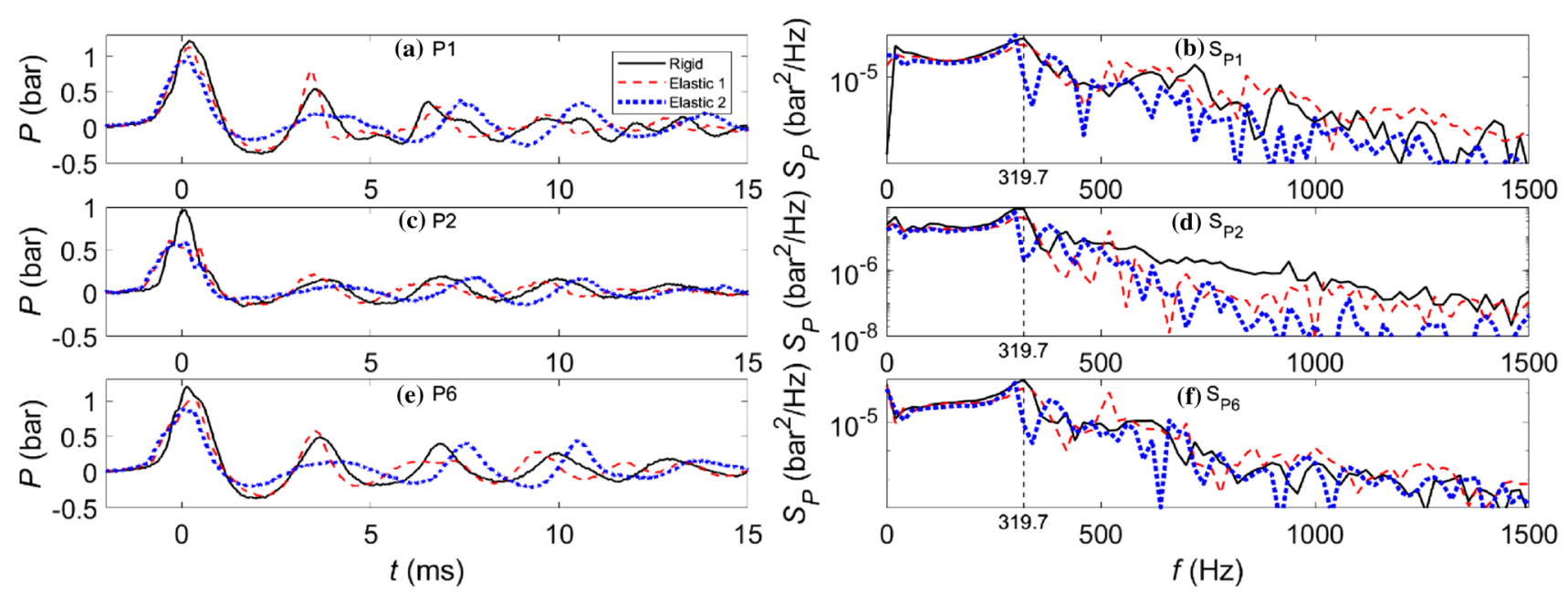

Fig. 8 Oscillations of pressures (left) and their spectra (right) due to impact of rigid and elastic plates in water $(v=1.28 \pm 0.07 \mathrm{~m} / \mathrm{s}, m=52 \mathrm{~kg})$. Note the different vertical scales
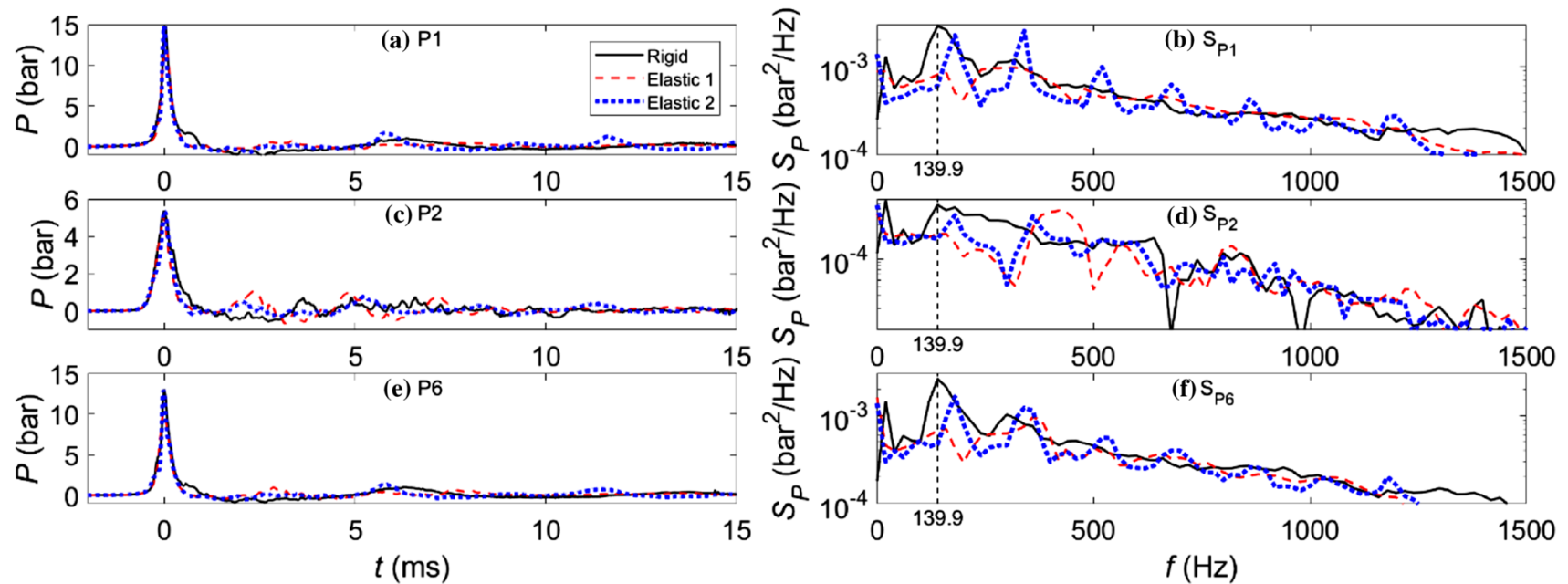

Fig. 9 Oscillations of pressures (left) and their spectra (right) due to impact of rigid and elastic plates in water $(v=4.08 \pm 0.15 \mathrm{~m} / \mathrm{s}, m=52 \mathrm{~kg})$. Note the different vertical scales 

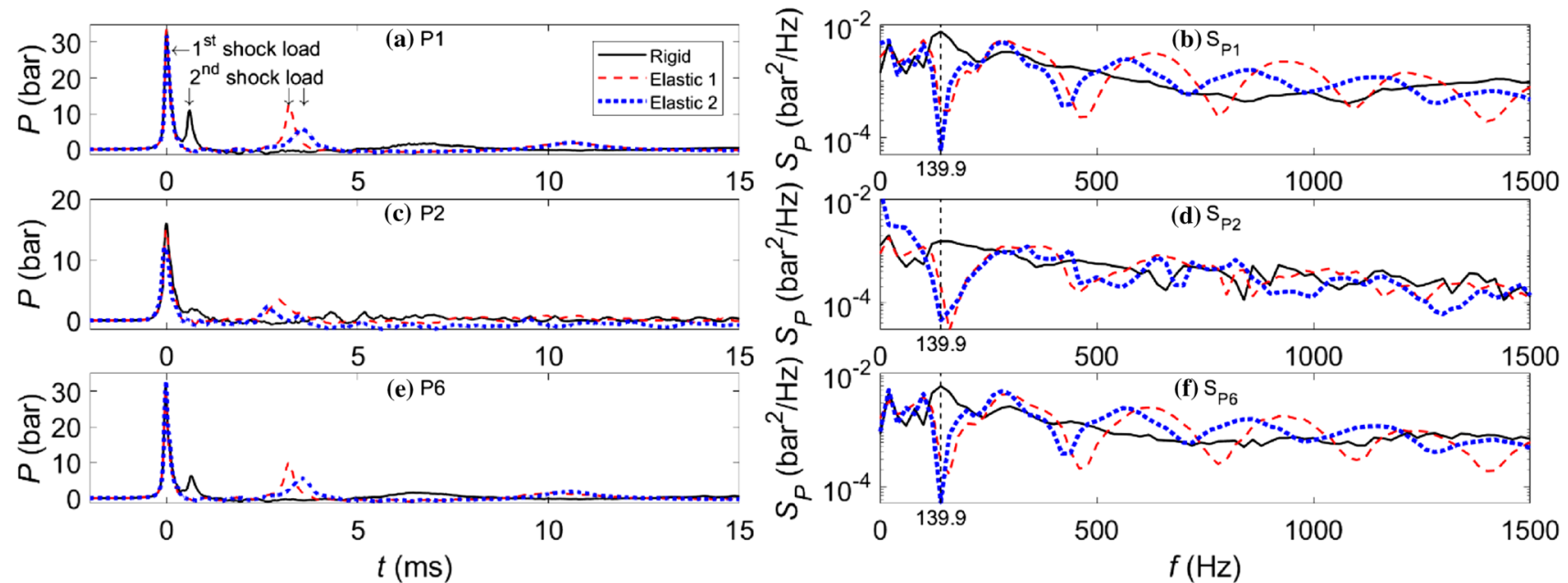

Fig. 10 Oscillations of pressures (left) and their spectra (right) due to impact of rigid and elastic plates in water $(v=6.96 \pm 0.18 \mathrm{~m} / \mathrm{s}, m=52 \mathrm{~kg})$. Note the different vertical scales
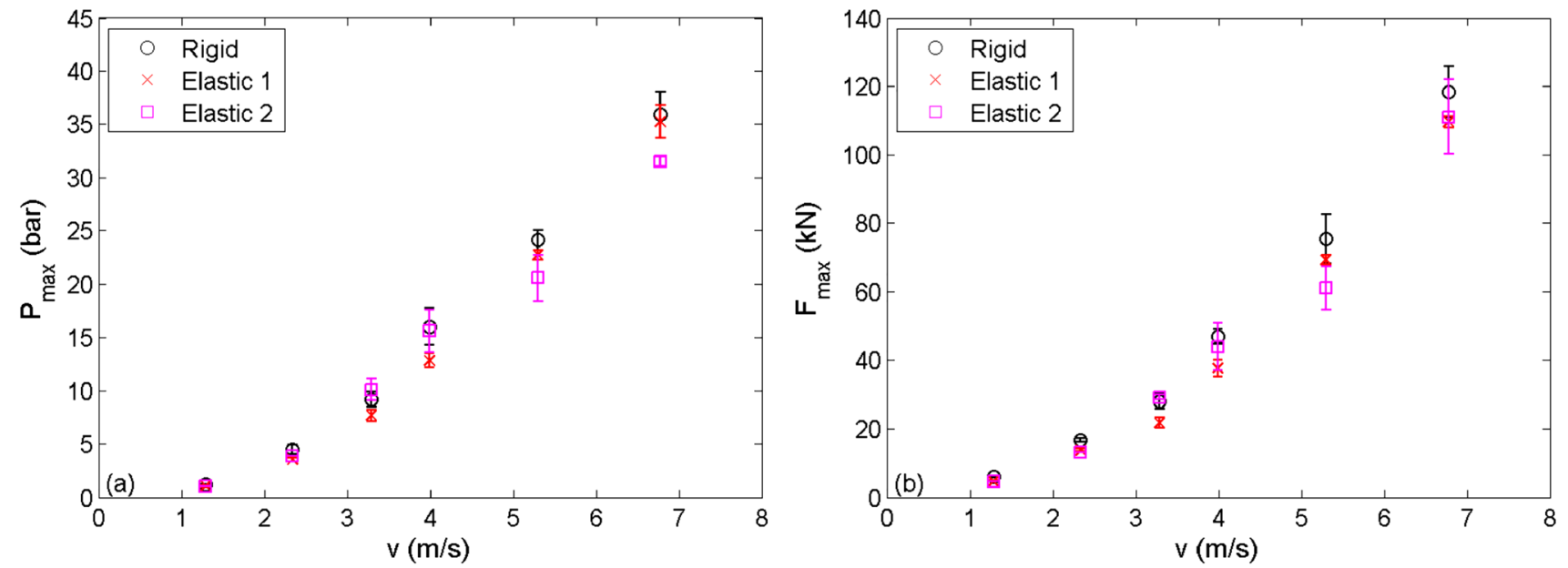

Fig. 11 Impact pressure P1 and force of rigid and elastic plates $(m=52 \mathrm{~kg})$

in Fig. $11 \mathrm{~b}$ for 3-10 repeats. In general, there is a slight reduction in impact pressure and force only at the higher velocities, beyond $5 \mathrm{~m} / \mathrm{s}$. This limited reduction may due to the stiffness of springs used to form the elastic plates 1 and 2. The results presented by Tenzer et al. (2015) also failed to show a clear trend of hydroelasticity effects on pressure peaks, with the body they tested also being relatively stiff. Stenius et al. $(2011 \mathrm{a}, \mathrm{b})$ showed that measured pressure magnitudes increase at the centre of the panel width of a wedge with increasing flexibility of the tested body with this trend being similar to their numerical simulations. They found a change of pressure magnitudes as a result of the local change in deadrise angle and impact velocity for a flexible body.

\subsubsection{Impulses (pressure and force) on rigid and elastic plates}

Impulse values can be obtained by integrating force or pressure over the duration of the impact. In the present study, the first impulse ( $I^{\text {first }}$ ) of the impact is defined as the impulse of the first positive phase of the impact, i.e. the area A1 in Fig. 12 and the total impulse $\left(I^{\text {total }}\right)$ is integrated from the start of the impact until the signal falls back to the noise level, i.e. the sum of the areas A1 to A8 in Fig. 12. It is noted that, the "total impulse" for the drop tests is calculated for a duration from the start time of an impact until the time when the impact plate was restrained by the rope used to stop the plate falling onto the basin floor. Therefore, the "total impulse" used in this analysis does not consider the entire motion of the object brought to rest and therefore there 
may be a difference between the total impulses for various impacts (Mai 2017; Mai et al. 2019a).

$I_{\mathrm{P}}^{\text {first }}$ and $I_{\mathrm{F}}^{\text {first }}$ of the rigid and elastic plates impact are presented in Fig. 13. The masses of the plates are all of $52 \mathrm{~kg}$. It is shown that $I_{\mathrm{P}}^{\mathrm{first}}$ and $I_{\mathrm{F}}^{\mathrm{first}}$ of the rigid plate are generally higher than those for the elastic plates. This can be seen most clearly at the high impact velocities beyond $4 \mathrm{~m} / \mathrm{s}$. However,

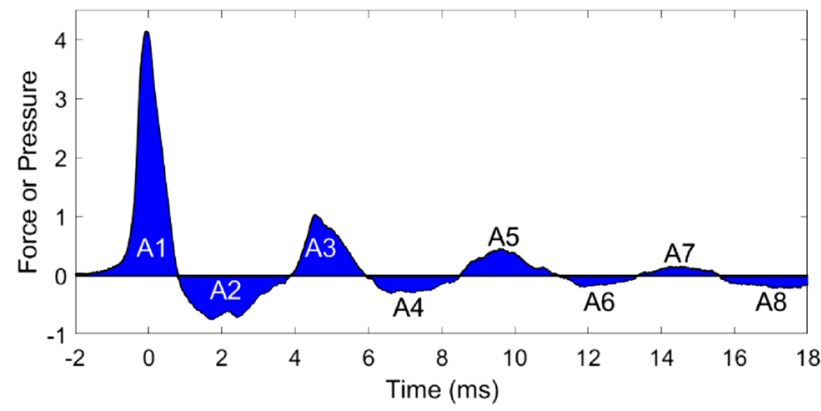

Fig. 12 Definition sketch for the first impulse $\left(I^{\text {first }}\right)$ and total impulse $\left(I^{\text {total }}\right)$

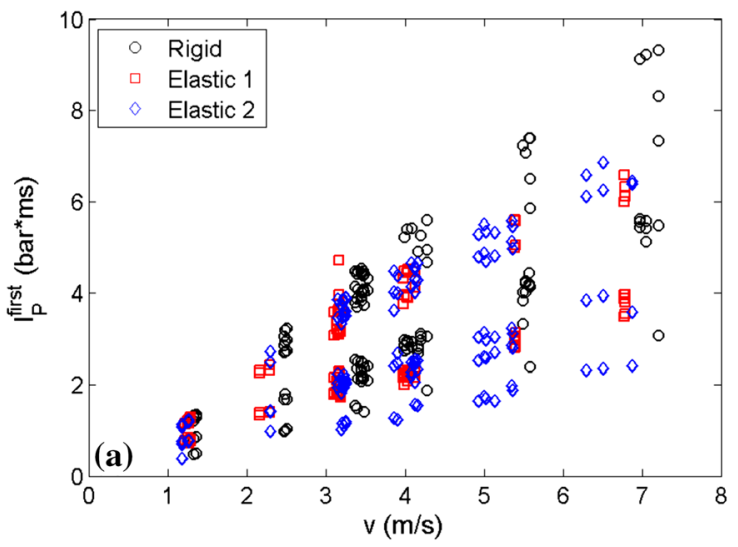

the total impulses of pressure and force $\left(I_{\mathrm{P}}^{\text {total }}\right.$ and $\left.I_{\mathrm{F}}^{\text {total }}\right)$ presented in Fig. 14 show there is no clear difference between the total impulses of the rigid and elastic plates.

\subsection{Hydroelasticity effects on wave impact on a vertical hull}

\subsubsection{Comparison of acceleration, force, deflection and pressures on the rigid and elastic walls}

Typical time histories of acceleration, force, pressure, and spring deflection on the rigid and elastic walls are presented in Figs. 15, 16 and in Appendix B. The corresponding FFT spectra are also presented in those figures. It can be clearly seen that there is a low oscillation frequency $(\sim 37 \mathrm{~Hz})$ after impact in the time histories and FFT spectra of acceleration, force and spring deflection of the tested walls (Figs. 15, 16 and in Appendix B). Evidence of this low frequency can also be seen in the pressure signals under high aeration and flip-through wave

Fig. $13 I_{\mathrm{P}}^{\text {first }}(\mathbf{a})$ and $I_{\mathrm{F}}^{\text {first }}(\mathbf{b})$ of the rigid and elastic plates impact in water $(m=52 \mathrm{~kg})$
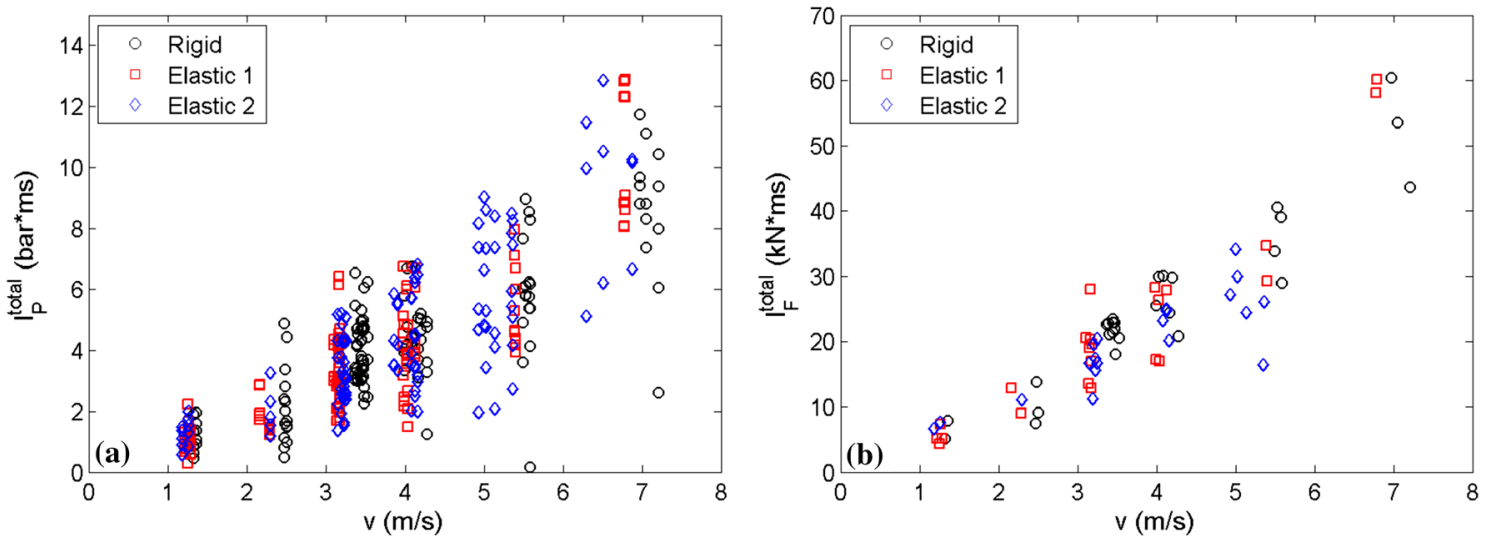

Fig. $14 I_{\mathrm{P}}^{\text {total }}(\mathbf{a})$ and $I_{\mathrm{F}}^{\text {total }}(\mathbf{b})$ of the rigid and elastic plates impact in water $(m=52 \mathrm{~kg})$ 

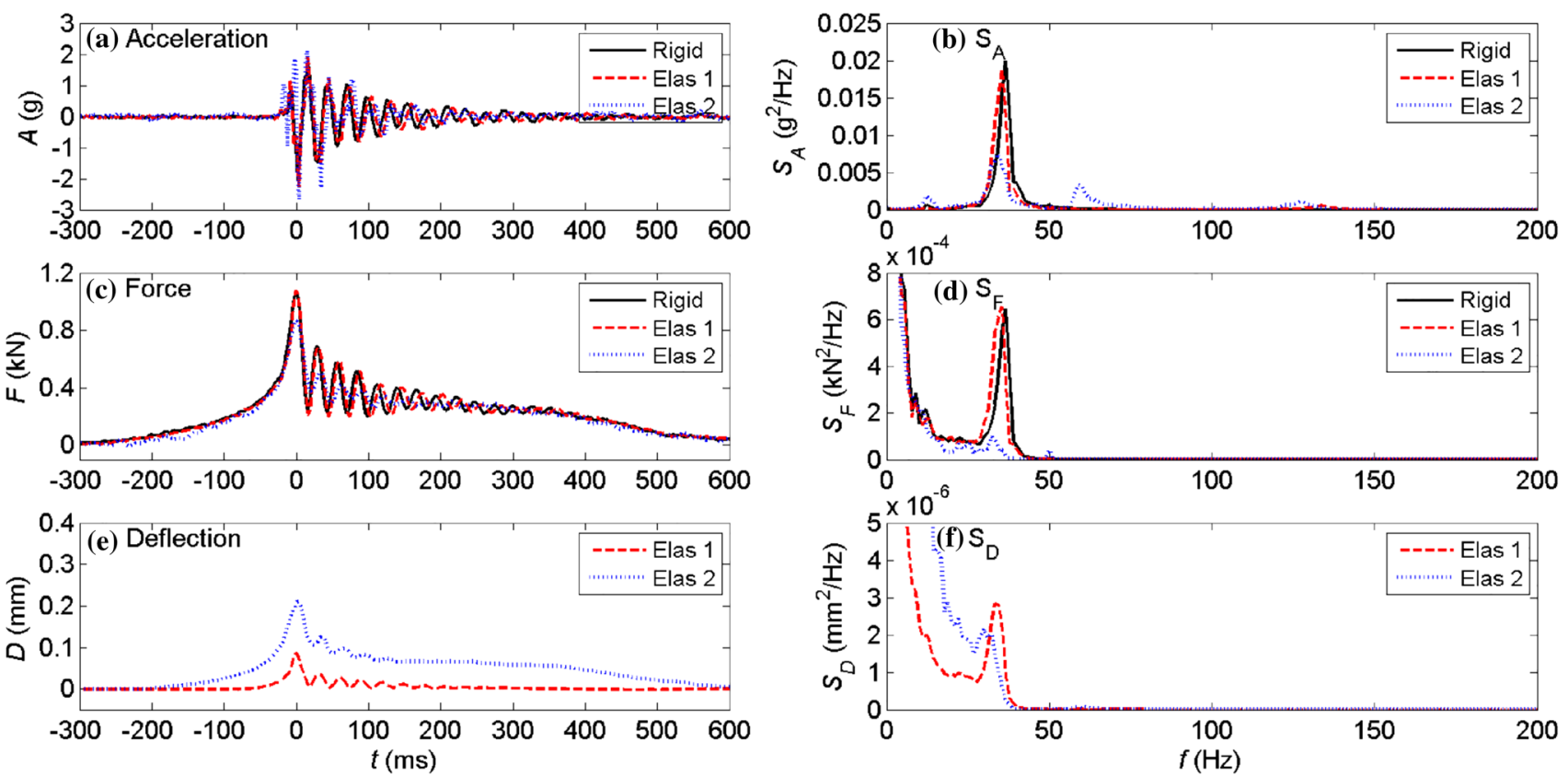

Fig. 15 Time histories (left) and their spectra (right) of acceleration, force and deflection due to flip-through impact
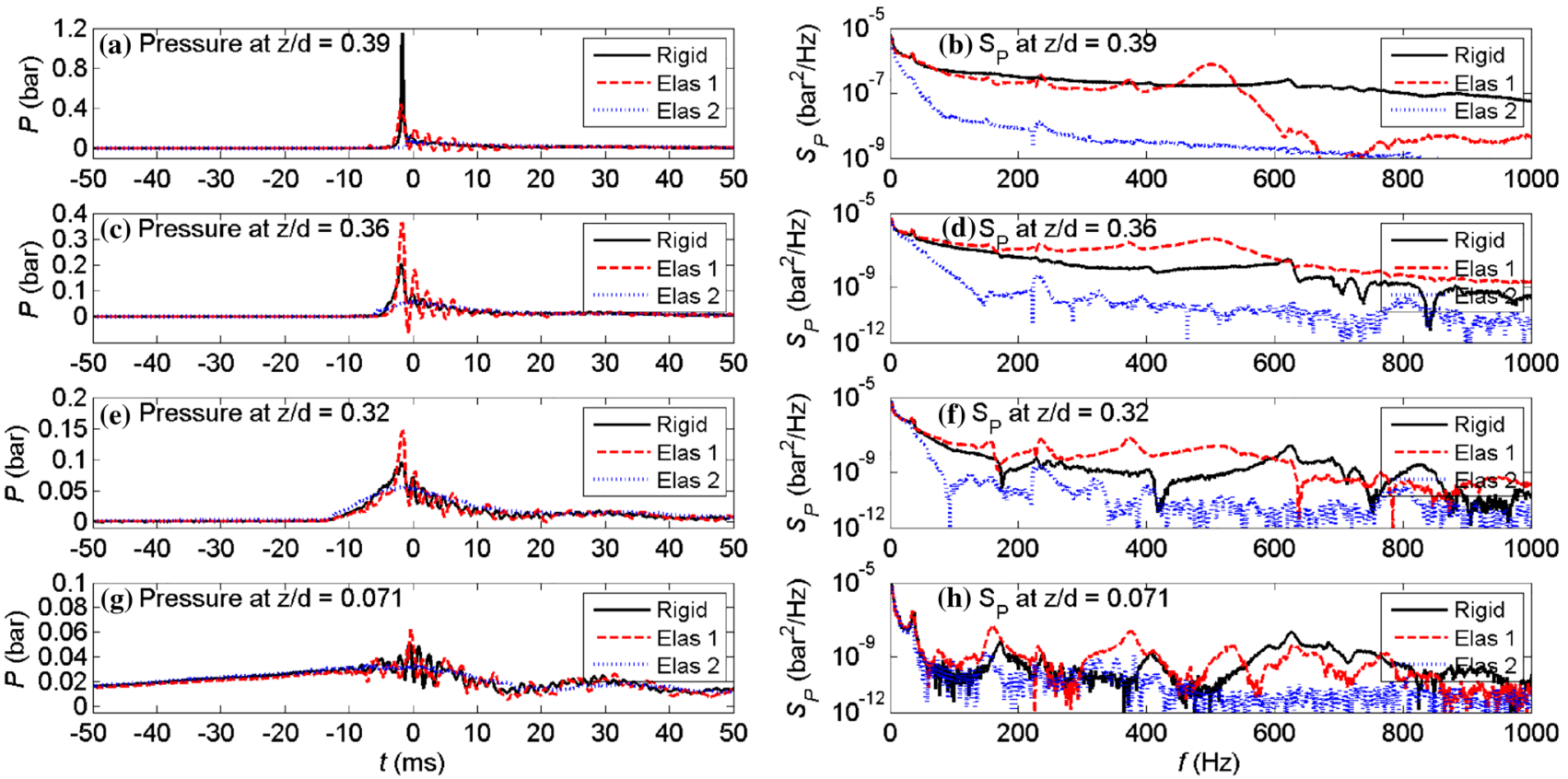

Fig. 16 Pressure time histories (left) and their spectra (right) due to flip-through wave impact on the walls. Note the different vertical scales

impacts on the rigid and elastic walls (Figs. 16 and 24). Using the theoretical natural frequency of air bubbles in water as derived by Minnaert (1933) and Hattori et al. (1994), the $37 \mathrm{~Hz}$ frequency of oscillation observed here corresponds to air-pocket and bubble radius of $88.2 \mathrm{~mm}$. As visualised observation of the impacts by high speed camera (Mai et al. 2019b), there are no large air-pockets or bubbles with radii of about $88.2 \mathrm{~mm}$. Therefore, it cannot be said that the $37 \mathrm{~Hz}$ frequency is due to air-pocket and bubbles under the impacts. This relatively low frequency is far from the dry natural frequencies of $25.3 \mathrm{~Hz}$ and 14.4 Hz for the elastic walls 1 and 2, respectively, but this 
$37 \mathrm{~Hz}$ frequency is identical to the $40 \mathrm{~Hz}$ natural frequency of the whole structure including the support frame, impact wall, plates 2-4 and four springs. The detailed estimation of dry natural frequency of the four springs and the impact wall is presented in Table 2 in Appendix A. Acceleration of the impact walls increases with increasing flexibility of the wall and there are higher oscillation frequencies for the more flexible walls (Figs. 15a, b, 21a, b, 23a, b, $25 \mathrm{a}, \mathrm{b})$. Maximum force of the wall also decreases with increasing flexibility of the wall, except for the slightly breaking wave impact whereas the maximum force on the elastic wall 1 is higher than that on the rigid wall (Fig. 25c). This reduction of the maximum force can be clearly seen for the high aeration and flip-through wave impacts (see Figs. 15c, 23c). As expected, deflection of springs increases significantly with decreasing stiffness of spring under the tested wave impacts (Figs. 15e, 21e, $23 \mathrm{e}, 25 \mathrm{e}$ ). Pressures on the tested walls are found to be very sensitive under wave impacts and it is difficult to assess how hydroelasticity affects the pressure on the walls by comparing single test cases between the tested walls (Figs. 16, 22, 24). However, for the slightly breaking wave, which is known to be more quasi-hydrostatic than the other wave impact types, as also found for the force on the wall, the pressures on the elastic wall 1 are higher than those on the rigid wall, although they are seen to decrease with the more flexible wall (Elastic wall 2), see Fig. 26. The respective FFT spectra are presented in the right hand plots in Figs. 16, 22, 24, 26 for the time histories of pressures presented in the left hand plots. The spectra are plotted on a logarithmic scale for the y-axis to show more detail of the spectral tail form.

\subsubsection{Impact pressure and impulse of wave impact}

The maximum pressures at various levels $(z / d=0.071$ to 0.39 , in which $d$ is the water depth and $z$ is the positive upward level of pressure sensor referring to SWL) are presented in Fig. 17 for different types of wave impact on the rigid and elastic walls. For the tested elastic wall 2, pressures
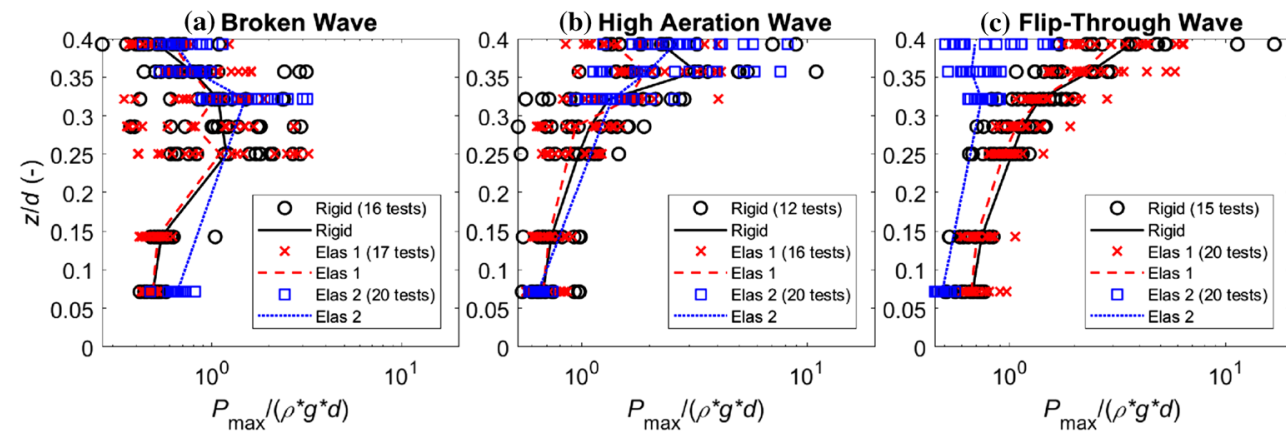

Fig. 17 Impact pressures $\left(P_{\max } / \rho g d\right)$ on the walls

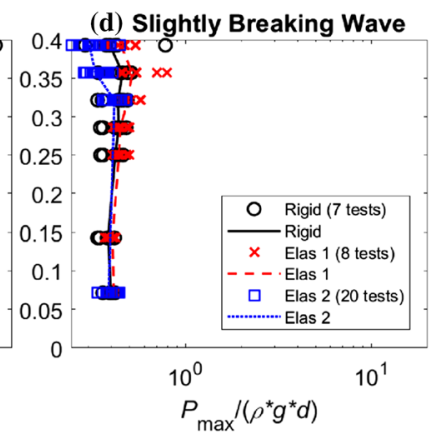
0.39 . The vertical axis is the dimensionless level $z / d$ of the measured points on the wall and SWL is represented by $z / d=0$. The horizontal axis is the logarithm of dimensionless impact pressure, $P_{\max } /(\rho g d)$. In each plot of Fig. 17, the black circle represents the impact pressures on the rigid wall, while the red cross and blue square are respectively for the elastic walls 1 and 2. The solid, dashed and dotted lines connect the mean values of the measured maximum pressure at each level on the rigid wall, elastic walls 1 and 2 , respectively. It can be seen from Fig. 17 that the distributions of the impact pressures on the tested walls are different under various wave impact types (broken, high aeration, flip-through and slightly breaking) and the highest impact pressures were attained at the levels above SWL which is previous works found the highest impact pressures occurred at and around SWL (Hattori et al. 1994; Oumeraci et al. 1993; Hull and Müller 2002; Bullock et al. 2007). This difference may be due to the use of focused wave groups here and by Hofland et al. (2011). At levels of $z / d=0.25$ to 0.32 , high impact pressures on the rigid and elastic walls were attained under broken wave impact (Fig. 17a). Under high aeration wave and flip-through impacts, the impact pressures are significantly higher further up the wall (greater $z / d$ ), except for the high aeration wave impact in which the medium value of the impact pressures at level $z / d=0.39$ is slightly smaller than that at level $z / d=0.36$ on both the rigid wall and the elastic wall 1 (Fig. 17b, c). For the high aeration case, the impact pressure appears to peak at level $z / d=0.36$, while for the flip-through the impact pressure continues to increase with distance up the wall. The highest impact pressure on the rigid wall and the elastic wall 1 were 1.15 bar $\left(P_{\max } / \rho g d=16.8\right)$ and 0.44 bar $\left(P_{\max } / \rho g d=6.4\right)$ which were both recorded at level $z / d=0.39$ under the flipthrough impacts (Fig. 17c). On the other hand, the highest impact pressure of $0.56 \mathrm{bar}\left(P_{\max } / \rho g d=8.2\right)$ was measured at $z / d=0.36$ on the elastic wall 2 under high aeration wave impact (Fig. 17b). Figure 17d illustrates the distribution of the impact pressures on the rigid and elastic walls under were measured at four levels of $z / d=0.071,0.32,0.36$ and similar to the finding by Hofland et al. (2011), while most 

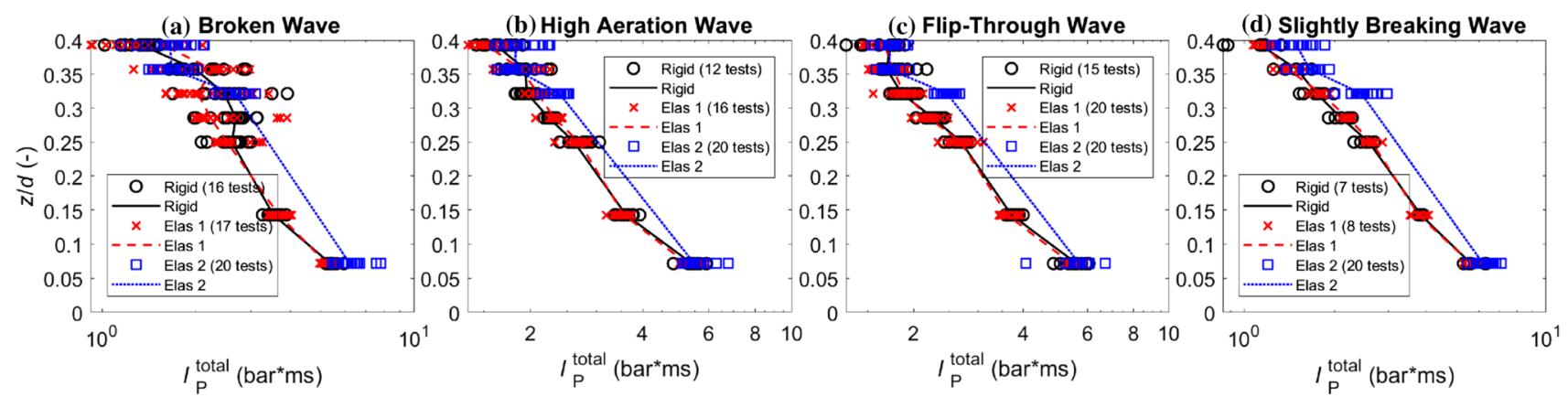

Fig. 18 Pressure impulses $\left(I_{\mathrm{P}}^{\text {total }}\right)$ on the walls

the slightly breaking wave impacts. The impact pressures at the high levels $(z / d=0.25$ to 0.39$)$ are slightly larger than those at lower levels for all the tested walls. The impact pressures due to the slightly breaking wave impacts are much lower than those due to other wave impact types (broken, high aeration and flip-through). Considering single impact events, the highest impact pressures on the rigid wall $\left(P_{\max }=1.15 \mathrm{bar}\right)$ are much higher than those on the elastic walls $\left(P_{\max }=0.44\right.$ bar for the elastic wall 1; $P_{\max }=0.56$ bar for the elastic wall 2). However, the medium values of all recorded impact pressures are more or less the same for the rigid and elastic walls at all levels, except the impact pressures on the elastic wall 2 are much smaller than those on the rigid wall and the elastic wall 1 under the flip-through impact (Fig. 17c). For the broken, high aeration and flipthrough wave impacts, large scatter of the impact pressures was found at high levels ( $z / d=0.25$ to 0.39 ) on the walls (Fig. 17a, b, c). The slightly breaking wave impact caused the smallest scatter of impact pressures at all levels and the spatial variation of the maximum pressures on the wall is simply related to the local hydrostatic pressures on the walls (Fig. 17d). The large scatter of the impact pressures on a vertical wall under different wave impacts were also observed in previous studies (Hattori et al. 1994; Oumeraci et al. 1993; Hull and Müller 2002; Bullock et al. 2007).

The total pressure impulses $\left(I_{\mathrm{P}}^{\text {total }}\right)$ were obtained by integrating pressure values over the impact duration. Figure 18 presents the total pressure impulses at different levels on the rigid and elastic walls under the tested wave impact types. The black circle, red cross and blue square markers represent the total pressure impulses on the rigid wall, the elastic walls 1 and 2, respectively. The line joining mean values of the total pressure impulses is also presented in each plot of Fig. 18. It can be seen that the total pressure impulses on the rigid wall (the black solid lines) are approximately the same on the elastic wall 1 (the red dashed lines) at all levels due to the tested wave impact types. On the elastic wall 2 , pressure impulses at levels from $z / d=0.071$ to 0.32 are much higher than those on the rigid wall and the elastic wall 1 due to all
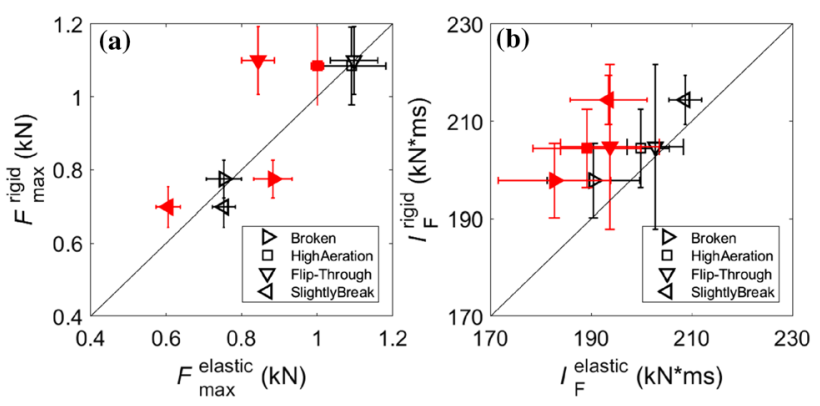

Fig. 19 a Impact forces and b total force impulses on the walls: elastic wall 1 vs. rigid wall (empty markers); elastic wall 2 vs. rigid wall (filled markers). The diagonal solid line is the 1:1 line

wave impact types (Fig. 18a-d). In general, the total pressure impulse decreases with increasing level on the walls and this is because of the submerged duration at lower levels being greater than those at higher levels even though the maximum pressure at the lower level is much smaller. This can be seen from the pressure time histories at different levels on the wall under wave impacts presented in the previous section (Fig. 16) and Appendix B (Figs. 22, 24, 26).

\subsubsection{Impact force and impulse of wave impact}

The mean impact force $\left(F_{\max }\right)$ and force impulse $\left(I_{\mathrm{F}}\right)$ on the rigid and elastic walls due to different wave impacts are presented in Fig. 19. In each plot, the horizontal axis represents the impact force (Fig. 19a) and total force impulse (Fig. 19b) on the elastic wall, while the vertical axes represent those on the rigid wall.

It can be seen from Fig. 19a that the mean impact forces on the rigid wall are the same as those on the elastic wall 1 for the tested impact types, except for the slightly breaking wave impact, whereas the impact force on the rigid wall is slightly smaller than that on the elastic wall 1 . In contrast, average impact forces on the elastic wall 2 are smaller than those on the rigid wall for the high aeration, flip-through and slightly breaking wave impacts. Due to the broken wave 
impact, the impact force on the elastic wall 2 is higher than that on the rigid wall.

Figure $19 \mathrm{~b}$ shows that as the elasticity of the wall increases, the mean total force impulse on the wall is larger for all tested impact types (the broken, high aeration, flipthrough and slightly breaking impacts). The scatter in the total force impulse (Fig. 19b) is much larger than that of the impact force (Fig. 19a). It is found that the difference in total force impulse is about $10 \%$ of the lowest total force impulse for all investigated wave impact types.

\subsubsection{Maximum deflection and impulse of springs}

The mean of the maximum deflections of the springs used for the elastic walls is presented in Fig. 20a from various repeats presented in previous sections. Due to the high aeration and flip-through impacts, the average deflections of the springs of the elastic wall 1 are approximately the same as each other $(\sim 0.09 \mathrm{~mm})$ and they are nearly double the average deflections due to the broken and slightly breaking wave impacts $(\sim 0.05 \mathrm{~mm})$. The highest average deflection of springs of the elastic wall 2 is found for the high aeration wave impact $(\sim 0.3 \mathrm{~mm})$. The average deflection due to the broken wave impact $(\sim 0.24 \mathrm{~mm})$ is higher than that of the flip-through impact $(\sim 0.2 \mathrm{~mm})$. Overall, the average deflections of the springs of the elastic wall 2 are much higher than those for the elastic wall 1 . These are simply due to the spring rate of the elastic wall 2 (CL51 $\times 254$ : $k=4 * 37.7 \mathrm{~N} / \mathrm{mm}$ ) is nearly one-third of the spring rate of the elastic wall 1 (CL51 $\times 102: k=4 * 98.5 \mathrm{~N} / \mathrm{mm})$. Because force is a function of deflection $(D)$ and structure stiffness $(k)$, then the deflection impulse can be another way to present the change in momentum under the impact. The total deflection impulses are presented in Fig. 20b, where we can see that the total deflection impulses of the elastic wall 2 are about ten times those of the elastic wall 1 . Similar to the force impulse, it is interesting to find that there is very little difference between the deflection impulses (about less than $8 \%$ of the lowest deflection impulse) found in all investigated wave impact types.
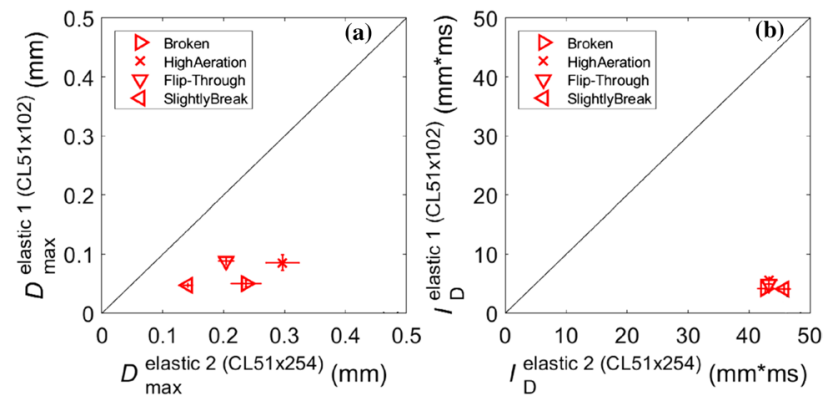

Fig. 20 a Maximum deflection and $\mathbf{b}$ total deflection impulses of the springs. The diagonal solid line is the 1:1 line

\section{Conclusions}

This experimental study investigates two different types of hydrodynamic interaction to shed light on the role of elasticity in slamming and wave impacts. These can have local and/or global effects on offshore structures and ships, and may cause structural vibrations and local damage. Two different experiments were conducted: (i) free-falling of rigid and elastic flat plates onto water surface, which is designed to represent severe slamming impacts with zero degree deadrise angle; (ii) different types of wave impacts on truncated vertical rigid and elastic walls. The elasticity of the tested plates and/or walls has an effect on the hydrodynamic impact loadings for both slamming and wave impacts, though for the slamming impacts this was for high impact velocities only. The total impact force has been observed to decrease on the elastic walls under the high aeration, flipthrough and slightly breaking wave impacts. However, the impact pressure only decreased under the flip-through wave impact. Furthermore, the elasticity also has an effect on the post-impact oscillations of the pressures for the slamming impacts, where the impulsive loadings of the first positive phase decreases with the elastic plates. Similarly, the total force impulse decreases with increasing elasticity of the wall for wave impacts, but the total pressure impulse on the wall increases for the more flexible wall. The effects of elasticity on hydrodynamic impact loadings need to be considered to assess the local/global loads which may cause local damage of a hull section or global structural response.

Acknowledgements This study is a part of the FROTH (Fundamentals and Reliability of Offshore sTructure Hydrodynamics) project supported by the Engineering and Physical Science Research Council (EPSRC Grant EP/J012866/1). The FROTH project was led by the University of Plymouth and the collaborative partners include Oxford University, University of Bath, City University London and the Manchester Metropolitan University. The authors gratefully acknowledge the financial support provided by EPSRC and useful discussions with the project partners.

Open Access This article is licensed under a Creative Commons Attribution 4.0 International License, which permits use, sharing, adaptation, distribution and reproduction in any medium or format, as long as you give appropriate credit to the original author(s) and the source, provide a link to the Creative Commons licence, and indicate if changes were made. The images or other third party material in this article are included in the article's Creative Commons licence, unless indicated otherwise in a credit line to the material. If material is not included in the article's Creative Commons licence and your intended use is not permitted by statutory regulation or exceeds the permitted use, you will need to obtain permission directly from the copyright holder. To view a copy of this licence, visit http://creativecommons.org/licenses/by/4.0/.

\section{Appendix A: estimation of natural frequency}

See appendix Tables 1, 2. 


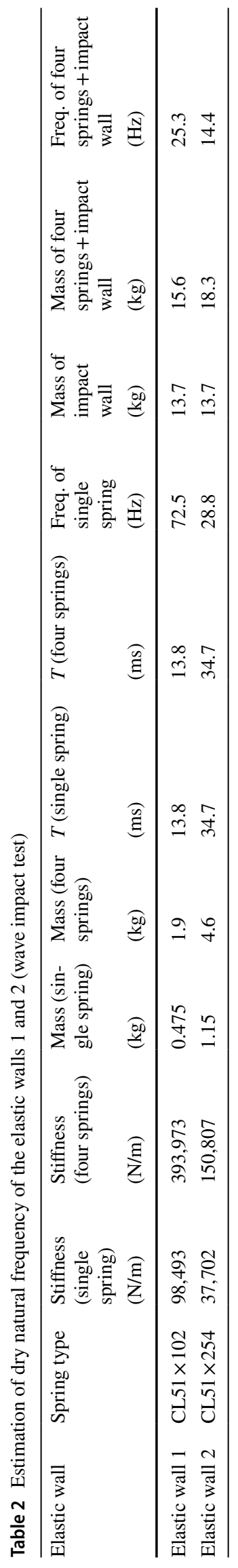




\section{Appendix B: wave impacts on rigid and elastic plates}

See appendix Figs. 21, 22, 23, 24, 25, 26.
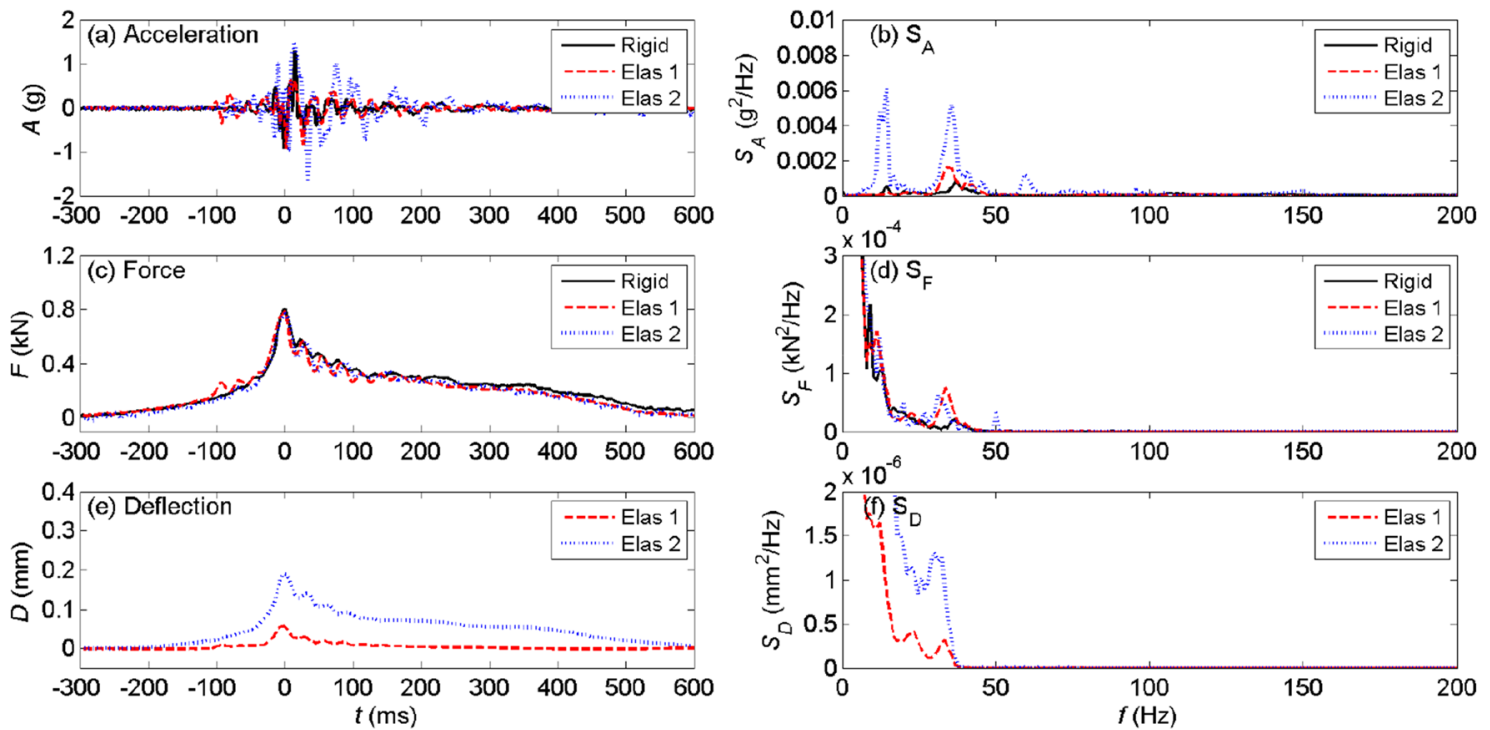

Fig. 21 Time histories (left) and their spectra (right) of acceleration, force and deflection due to broken wave impact
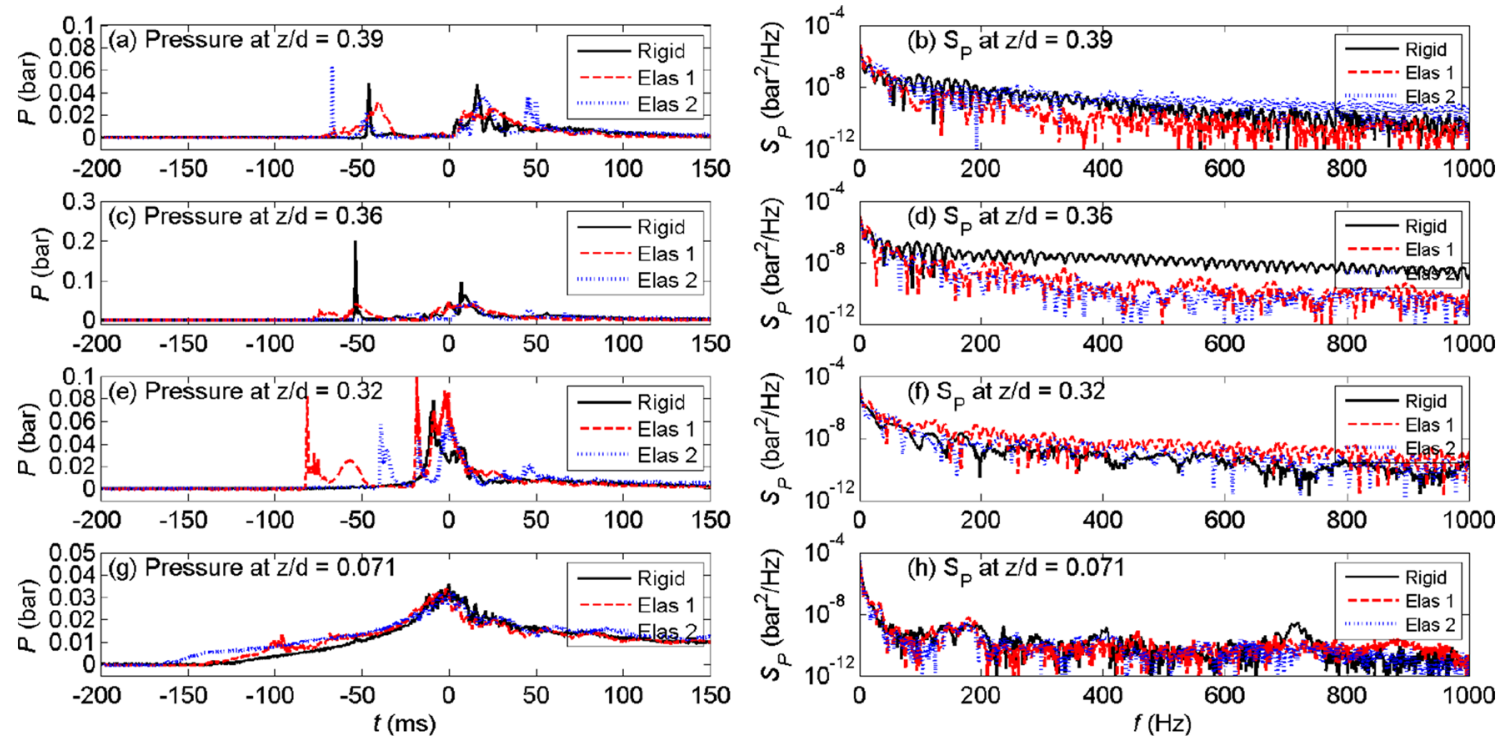

Fig. 22 Pressure time histories (left) and their spectra (right) due to broken wave impact on the walls. Note the different vertical scales 

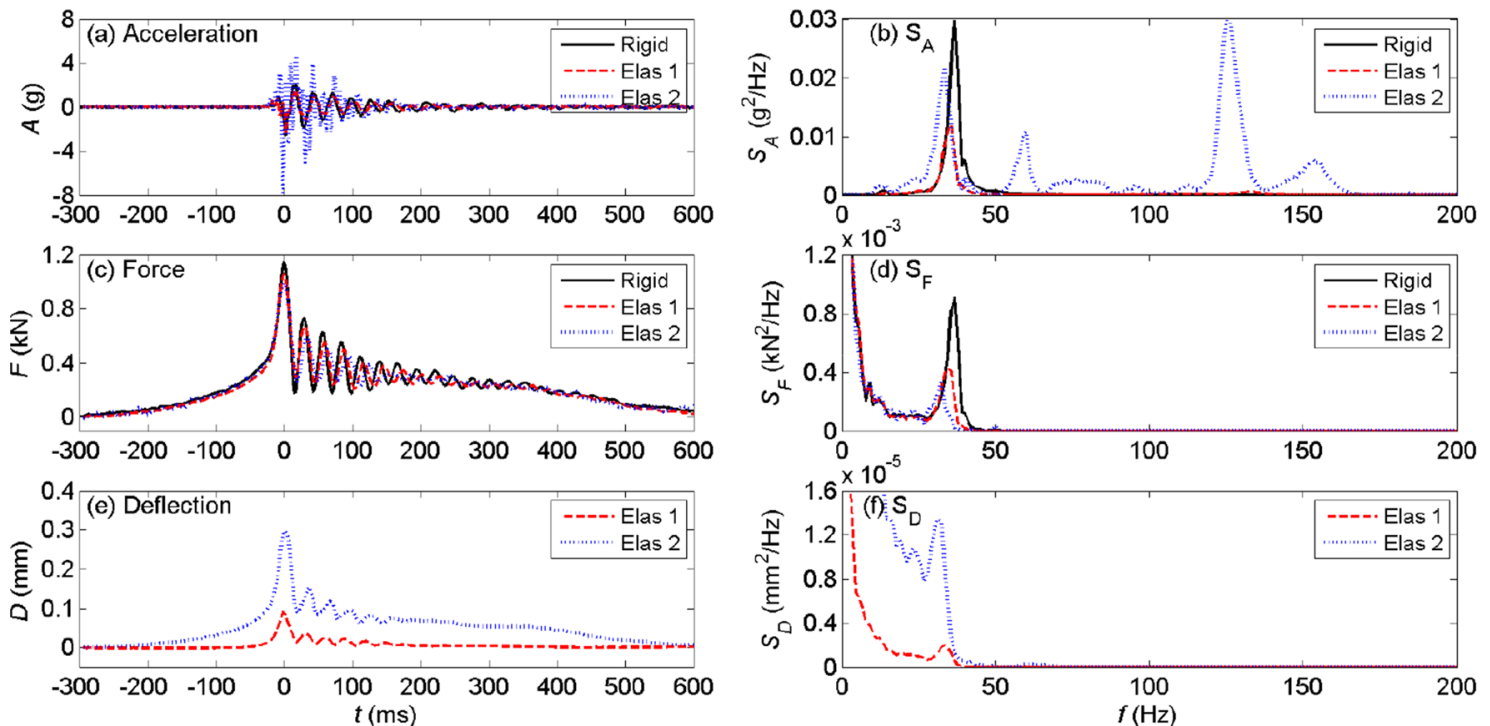

Fig. 23 Time histories (left) and their spectra (right) of acceleration, force and deflection due to high aeration impact
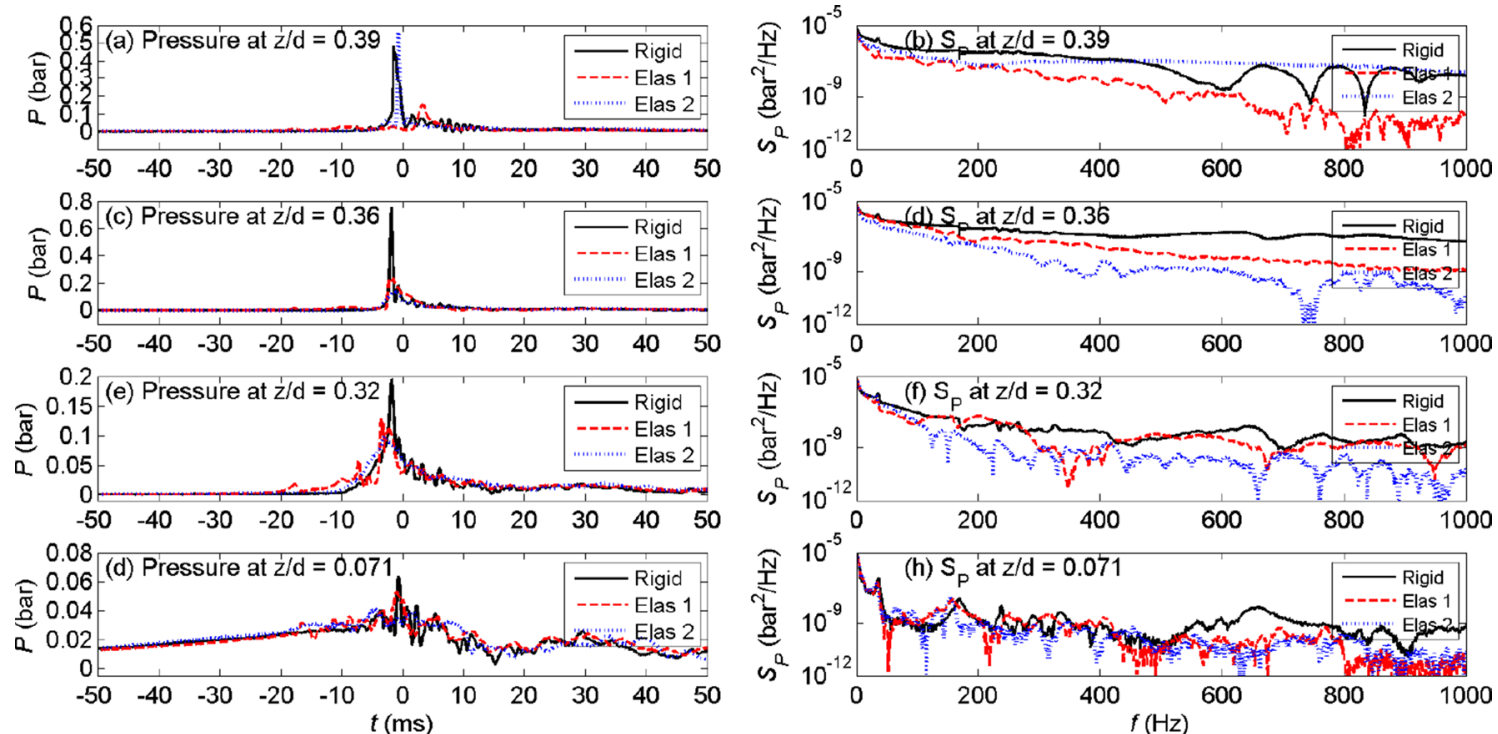

Fig. 24 Pressure time histories (left) and their spectra (right) due to high aeration wave impact on the walls. Note the different vertical scales 

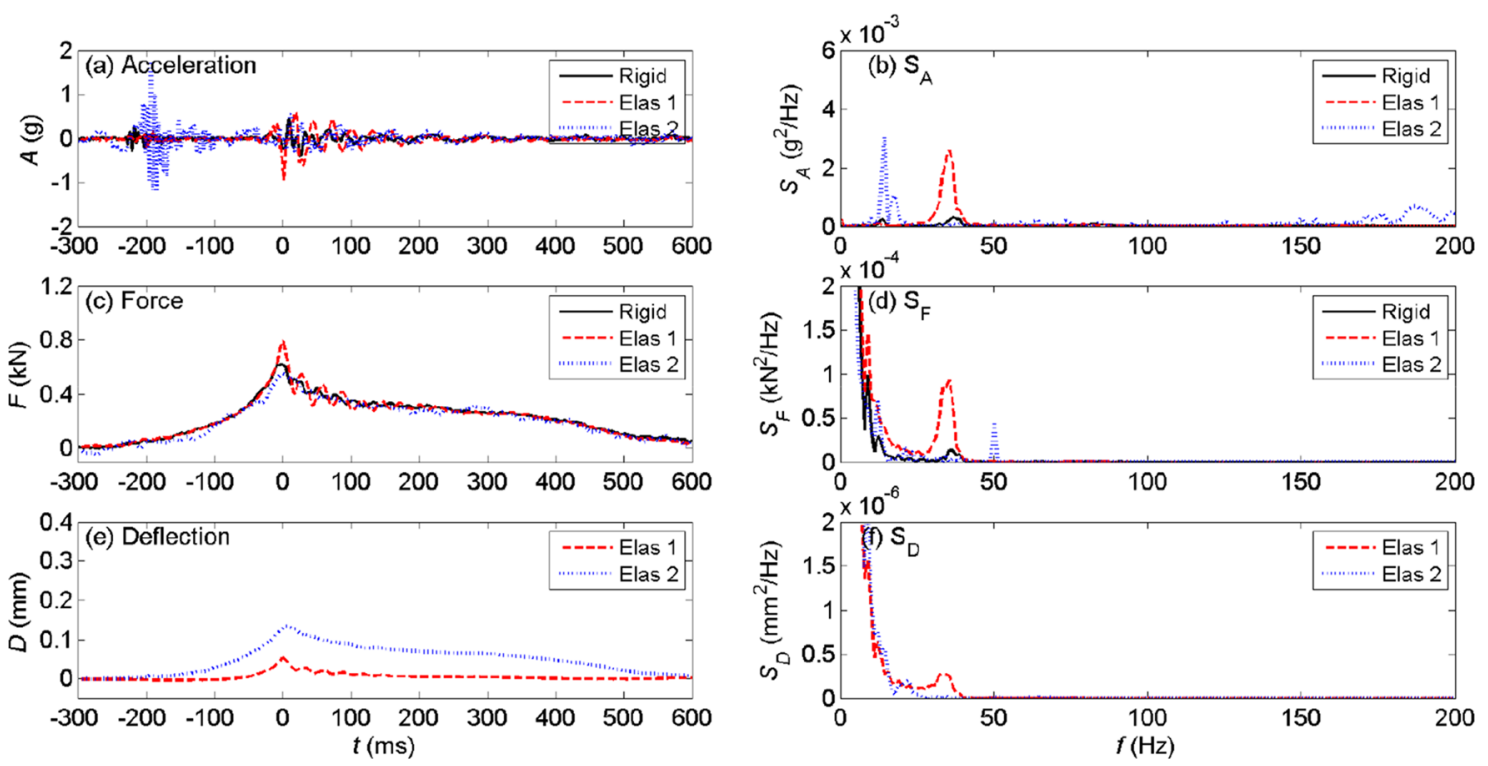

Fig. 25 Time histories (left) and their spectra (right) of acceleration, force and deflection due to slightly breaking wave impact
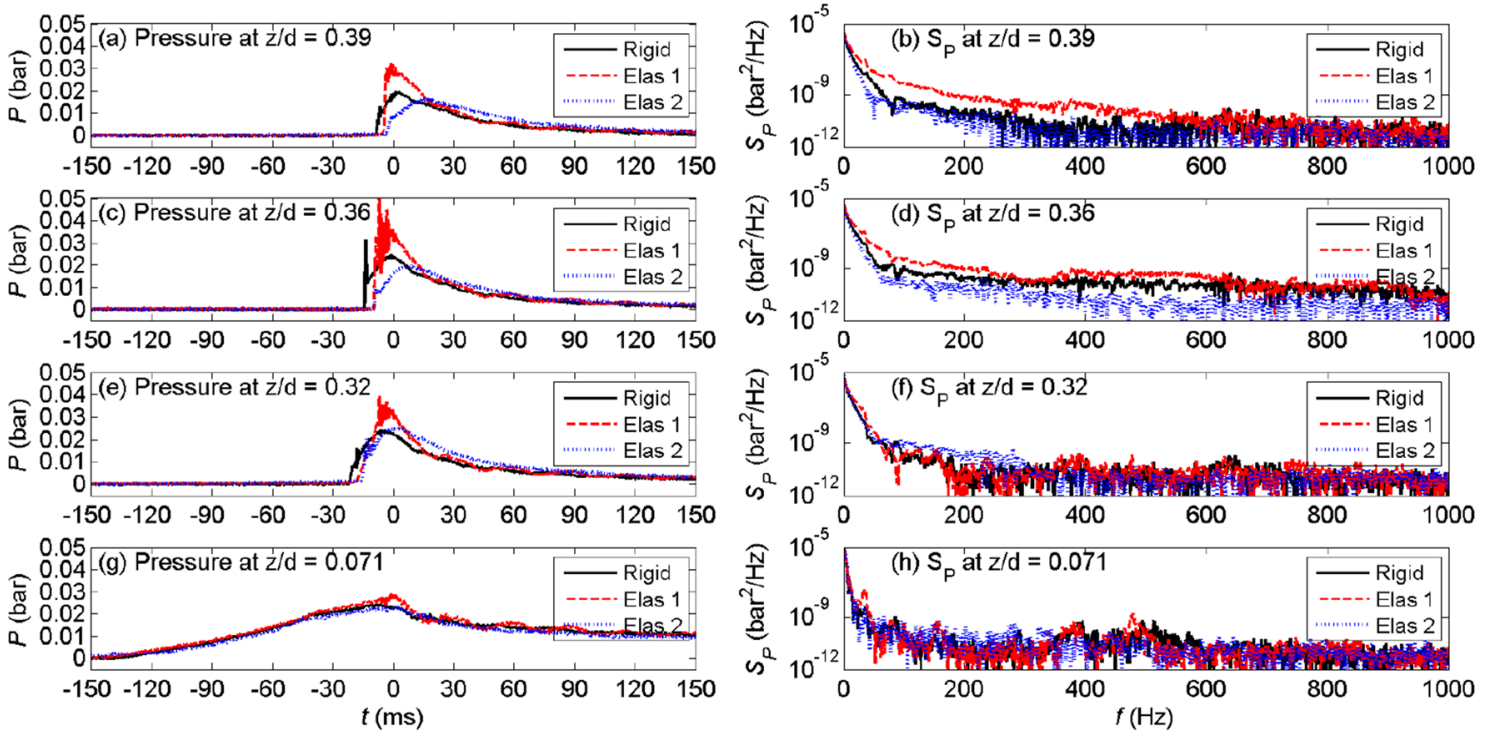

Fig. 26 Pressure time histories (left) and their spectra (right) due to slightly breaking wave impact on the walls. Note the different vertical scales

\section{References}

Aarsnes J (1994) An experimental investigation of the effect of structural elasticity on slamming loads and structural responses. Technical report MARINTEK A/S, Trondheim

Battley M, Allen T, Pehrson P, Stenius I, Rosen A (2009) Effects of panel stiffness on slamming responses of composite hull panels. In: 17th International conference on composite materials, ICCM17, Edinburgh International Convention Centre (EICC), Edinburgh, UK
Bishop R, Price W (1979) Hydroelasticity of ships. Cambridge University Press, Cambridge

Bullock GN, Obhrai C et al (2007) Violent breaking wave impacts. Part 1: results from large-scale regular wave tests on vertical and sloping walls. Coast Eng 54(8):602-617

Chuang S (1970) Investigation of impact of rigid and elastic bodies with water. Naval Ship Research and Development Center: Report No. 3248

Faltinsen OM (1997) The effect of hydroelasticity on ship slamming. Philos Trans R Soc Lond A Math Phys Eng Sci 355(1724):575-591 
Faltinsen O (2000) Hydroelastic slamming. J Mar Sci Technol 5(2):49_ 65. https://doi.org/10.1007/s007730070011

Faltinsen OM (2014) Hydrodynamics of marine and offshore structures. J Hydrodyn Ser B 26(6):835-847

Faltinsen O, Landrini M et al (2004) Slamming in marine applications. J Eng Math 48(3-4):187-217

Hattori M, Arami A et al (1994) Wave impact pressure on vertical walls under breaking waves of various types. Coast Eng 22(1-2):79-114

Hofland B, Kaminski M, Wolters G (2011) Large scale wave impacts on a vertical wall. Coast Eng Proc 1(32):15. https://doi.org/10.9753/ icce.v32.structures. 15

Hull P, Müller G (2002) An investigation of breaker heights, shapes and pressures. Ocean Eng 29(1):59-79

Kimmoun O, Malenica et al. (2009) Fluid structure interactions occurring at a flexible vertical wall impacted by a breaking wave. Proc. of 19th international offshore and polar engineering conference, 21-26 July, Osaka, Japan

Kimmoun O, Ratouis A, Brosset L (2010) Sloshing and scaling: experimental study in a wave canal at two different scales. Proceeding of the 20th international offshore and polar engineering conference (ISOPE 2010), Beijing, China

Kvålsvold J (1994) Hydroelastic modelling of wet-deck slamming on multi-hull vessels. Mta-report 1994: 100, Department of Marine Hydrodynamics, The Norwegian Institute of Technology, Norway

Lewison G, Maclean WM (1968) On the cushioning of water impact by entrapped air. J Ship Res 12(2):116-130

Ma ZH, Causon DM, Qian L, Mingham CG, Mai T, Greaves D, Raby A (2016) Pure and aerated water entry of a flat plate. Phys Fluids 28(1):016104. https://doi.org/10.1063/1.4940043

Mai T (2017) On the role of aeration, elasticity and wave-structure interaction on hydrodynamic impact loading. PhD thesis at Plymouth University. https://hdl.handle.net/10026.1/9884. Accessed 31 Aug 2017

Mai T, Greaves D, Alison R (2014) Aeration effects on impact: drop test of a flat plate. Proceedings of the 24th International ocean and polar engineering conference (ISOPE2014), Busan, Korea. 3:703-709

Mai T, Hu ZZ, Greaves D, Alison R (2015) Investigation of hydroelasticity: wave impact on a truncated vertical wall. Proceedings of the 25th international ocean and polar engineering conference (ISOPE2015), Hawaii, USA. 3:647-654

Mai T, Mai C, Alison R, Greaves DM (2019a) Aeration effects on water-structure impacts: part 1 Drop plate impacts. Ocean Eng 193:106600. https://doi.org/10.1016/j.oceaneng.2019.106600

Mai T, Mai C, Alison R, Greaves DM (2019b) Aeration effects on water-structure impacts: Part 2. Wave impacts on a truncated vertical wall. Ocean Eng 186:106053. https://doi.org/10.1016/j.ocean eng.2019.05.035
Mayer H, Krechetnikov R (2018) Flat plate impact on water. J Fluid Mech 850:1066-1116. https://doi.org/10.1017/jfm.2018.461

Minnaert M (1933) On musical air bubbles and the sounds of runningwater. Philos Mag 16:235-248

Oumeraci H, Klammer P et al (1993) Classification of breaking wave loads on vertical structures. J Waterw Port Coast Ocean Eng 119(4):381-397

Stenius I (2009) Hydroelasticity in marine hull bottom panels-modeling and characterization. KTH, Stockholm

Stenius I, Rosén A, Battley M, Allen T, Pehrson P (2011a) Hydroelastic effects in slamming loaded panels. In 11th. International conference on fast sea transportation (FAST 2011), Honolulu, Hawaii, USA (pp. 644-652)

Stenius I, Rosén A, Kuttenkeuler J (2011b) Hydroelastic interaction in panel-water impacts of high-speed craft. Ocean Eng 38(2-3):371-381

Stenius I, Rosén A, Battley M, Allen T (2013) Experimental hydroelastic characterization of slamming loaded marine panels. Ocean Eng 74:1-15

Temarel P (2008) "Hydroelasticity of ships: taking stock and moving forward. In: 22nd Asian-Pacific technical exchange and advisory meeting on marine structures, TEAM 2008, Istanbul, Turkey

Tenzer M, MoctarSchellin OETE (2015) Experimental investigation of impact loads during water entry. Ship Technol Res 62(1):47-59

Tromans PS, Anaturk AR, Hagemeijer P (1991) A new model for the kinematics of large ocean waves - application as a design wave. Proc. 1st Int. Offshore and Polar Eng. Conf., Edinburgh, UK, 11-16 August, 64-71

Verhagen JHG (1967) The impact of a flat plate on a water surface. J Ship Res 10:211-223

von Karman T (1929) The impact on seaplane floats during landing. National Advisory Committee for Aeronautics. Technical Note, vol. 321

Wagner H (1932) Über Stoß- und Gleitvorgänge an der Oberfläche von Flüssigkeiten. ZAMM - Journal of Applied Mathematics and Mechanics/Zeitschrift für Angewandte Mathematik und Mechanik 12(4):193-215

Williams MO (2008) Wave mapping in UK waters: Supporting document. Health and Safety Executive, Research Report RR621, pp 38

Zhu L (1995) Structural response of ship plates in slamming-drop test results and analysis. University of Glasgow Department of Naval Architecture and Ocean Engineering-Reports-NAOE, Glasgow

Publisher's Note Springer Nature remains neutral with regard to jurisdictional claims in published maps and institutional affiliations. 